City University of New York (CUNY) CUNY Academic Works

Spring 5-12-2015

\title{
Estimating Stormwater Runoff for Community Gardens in New York City
}

Mara Gittleman

\section{How does access to this work benefit you? Let us know!}

More information about this work at: https://academicworks.cuny.edu/hc_sas_etds/2

Discover additional works at: https://academicworks.cuny.edu

This work is made publicly available by the City University of New York (CUNY).

Contact: AcademicWorks@cuny.edu 


\section{Estimating Stormwater Runoff for Community Gardens in New York City by \\ Mara Gittleman}

Submitted in partial fulfillment

of the requirements for the degree of

Master of Arts in Geography, Hunter College

The City University of New York

2015

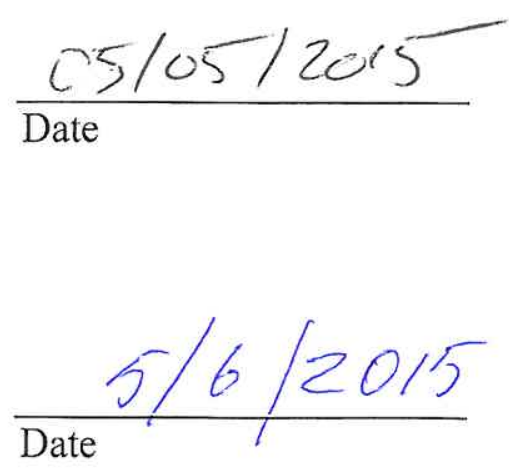

Thesis Sponsor:

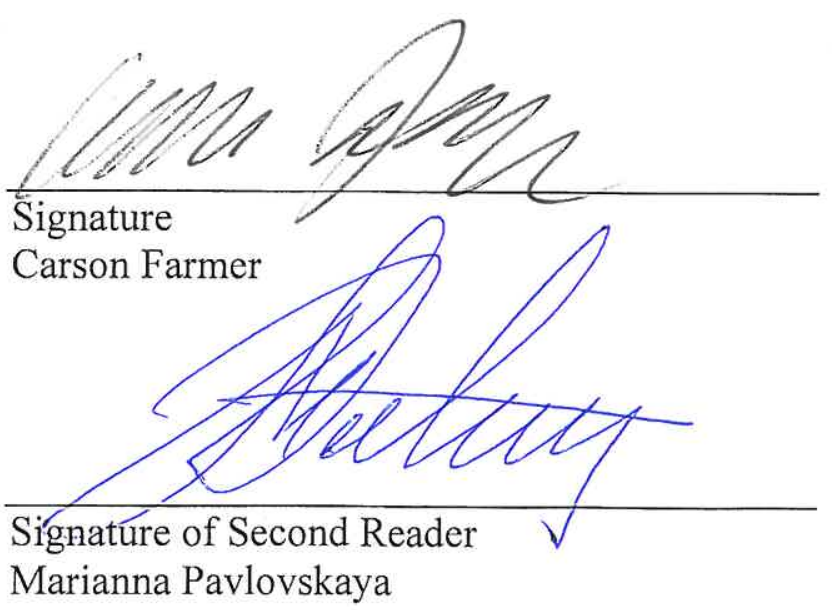




\section{DEDICATION}

Dedicated to the New York City Community Garden Coalition, whose mission is to promote the preservation, creation, and empowerment of community gardens through education, advocacy, and grassroots organizing. 


\section{ACKNOWLEDGEMENTS}

The focus of this thesis arose in collaboration with leaders of the New York City Community Garden Coalition out of acknowledgement of the dearth of useful data about the ecosystem services provided by community gardens. This thesis is written in gratitude of the work they do every day to support community managed green space.

This thesis would not be possible without the support of my advisor and primary reader, Dr. Carson Farmer, who helped guide and frame the research focus and the methodology throughout the process. I also thank Marianna Pavlovskaya for advising this thesis, and the rest of the faculty in the Geography Department at Hunter College for their support and guidance throughout my tenure as a student. 


\section{Table of Contents}

\begin{tabular}{lr} 
DEDICATION & 2 \\
\hline
\end{tabular}

\begin{tabular}{lc} 
ACKNOWLEDGEMENTS & 3 \\
\hline
\end{tabular}

LIST OF FIGURES

\begin{tabular}{lr} 
LIST OF TABLES & 6 \\
\hline
\end{tabular}

\begin{tabular}{lr} 
INTRODUCTION & 8 \\
\hline
\end{tabular}

$\begin{array}{lr}\text { STATE OF CiTIES } & 10\end{array}$

\begin{tabular}{lr} 
ECOSYSTEM SERVICES & 14 \\
\hline
\end{tabular}

ECOSYSTEM SERVICES IN NYC $\quad 16$

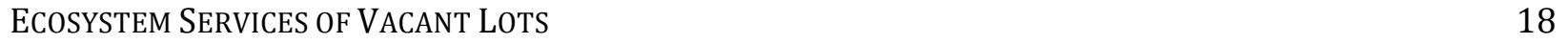

ECOSYSTEM SERVICES OF COMMUNITY GARDENS 21

\begin{tabular}{ll} 
STUDY AREA & 23 \\
\hline
\end{tabular}

COMMUNITY GARDENS IN NEW YORK CITY

GREEN INFRASTRUCTURE $\quad 33$

\begin{tabular}{ll} 
METHODS \& RESULTS & 41 \\
\hline
\end{tabular}

CALCULATING STORMWATER RUNOFF VOLUME $\quad \mathbf{4 1}$

HYDROLOGIC SOIL GROUP $\quad 43$

COMMUNITY GARDEN DATA $\quad 44$

JOINING WITH LAND COVER DATA

STORMWATER RUNOFF IN COMMUNITY GARDENS $\quad \mathbf{5 2}$

M1: REPLICATING METHODS FROM THE LITERATURE

M2: AN ALTERNATE APPROACH $\quad 59$

CASE STUDY: GARDENS ON LAND IN HPD JURISDICTION

\begin{tabular}{ll} 
DISCUSSION & 71 \\
\hline
\end{tabular}

\begin{tabular}{ll} 
CONCLUSIONS & $\mathbf{7 7}$ \\
\hline
\end{tabular}

\begin{tabular}{ll} 
APPENDIX A & 81 \\
\hline
\end{tabular}

\begin{tabular}{lc} 
APPENDIX B & 83 \\
\hline
\end{tabular}

\begin{tabular}{lc} 
REFERENCES & 86 \\
\hline
\end{tabular} 


\section{LIST OF FIGURES}

Figure 1: Figure 6C from McPherson, Kremer, and Hamstead (2013). H-L clusters represent areas of high social need and low ecological value. These areas are thus identified as priority areas for improved ecosystem services.

Figure 2: Community gardens in New York City (GrowNYC 2015)............................................ 28

Figure 3: Priority CSO Tributary Areas Map (Claro et al. 2013) ………………………………..... 37

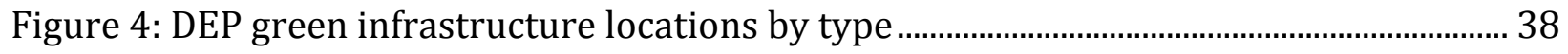

Figure 5: Community gardens and DEP green infrastructure locations ..................................... 39

Figure 6: Community garden soil hydrologic groups. A/D, B/D, C/D include some impervious surface area (SSURGO) ....................................................................................... 46

Figure 7: El Centro Rincon Criollo Community Garden in the Bronx: Incorrect land cover

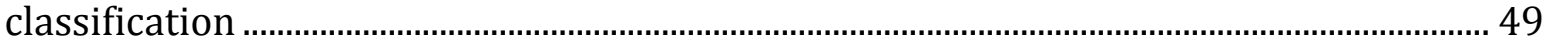

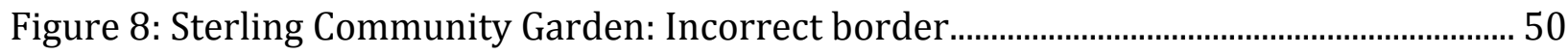

Figure 9: Histogram showing the distribution of community garden areas .............................. 55

Figure 10: $Q$ values for vacant lots, community gardens, and residential lots .......................... 57

Figure 11: Scatterplot of raised beds areas and garden areas (square feet) with lines fitted to three models: linear, second order polynomial, and third order polynomial ............. 63

Figure 12: Side-by-side comparison of $Q$ values for M1 and M2 methods.................................. 67 


\section{LIST OF TABLES}

Table 1: Four hydrologic soil groups as defined in USDA TR-55 (Table 3-3, 1986) .............. 44

Table 2: Curve numbers for open space, bare soil, and paved areas (USDA 1986)................ 48

Table 3: Runoff curve numbers for gardens and swales (Center for Neighborhood

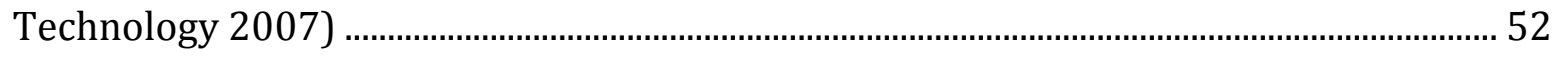

Table 4: Curve numbers for residential lots from Table 2-2 in TR-55 (USDA 1986) ............. 52

Table 5: Runoff for a 1.5" rain event ........................................................................................... 54

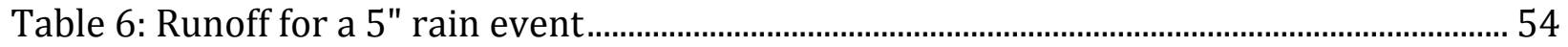

Table 7: Maximum estimates for runoff ...................................................................................... 58

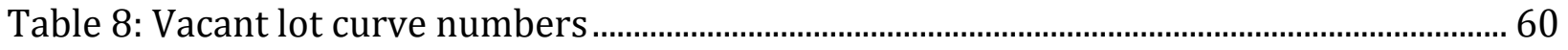

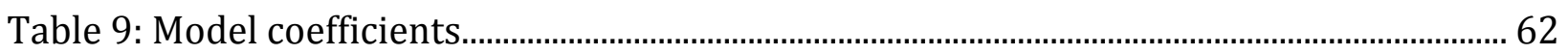

Table 10: Side-by-side comparison of $Q$ values for M1 and M2 methods................................... 65

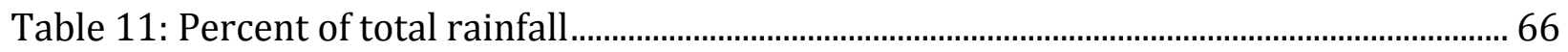

Table 12: Stormwater runoff and retention from 17 community gardens in HPD jurisdiction included in the January 2014, 2015 Request for Qualifications, with comparisons to

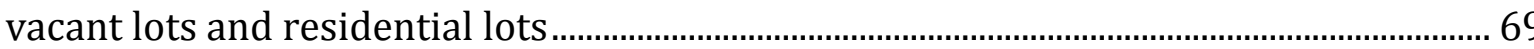

Table 13: Mean and maximum percent runoff for vacant lots and community gardens, as

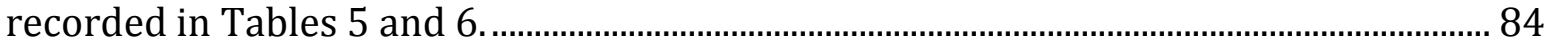

Table 14: $G d$ and $P d$ values for the difference in runoff between vacant lots and

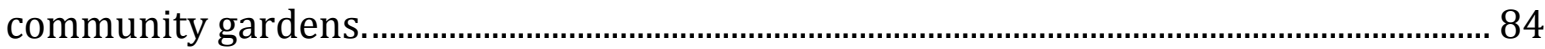


Table 15: Mean and maximum percent runoff for residential lots and community gardens, as recorded in Tables 5 and 6.

Table 16: $G d$ and $P d$ values for the difference in runoff between residential lots and

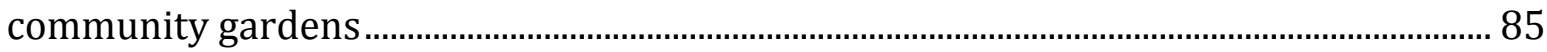




\section{INTRODUCTION}

Community gardens are built and managed by local residents on vacant land, often as acts of resistance to urban decline and disinvestment. They have a number of documented benefits, particularly in the social realm: they have been shown to improve community stability, reduce crime, and provide a number of health benefits (Smith and Kurtz 2003; Saldivar-Tanaka and Krasny 2004; Lawson 2005; Wakefield et al. 2007; Lin, Philpot, and Jha 2015). While much of the literature also cites community gardens as providing environmental benefits for cities, there is very little research actually quantifying these benefits. Despite the numerous urban ecosystem services these spaces provide, some municipalities, including New York City, do not consider community gardens as part of their plans for open space and green infrastructure. Without an ecosystems services framework, the case for community gardens is often framed around financial trade-offs with other types of urban land-use, such as housing (Lin, Philpot, and Jha 2015).

One of the biggest challenges of maintaining a healthy urban ecosystem is stormwater. New York City's sewer system relies on combined sewer overflows (CSOs), which release raw sewage and stormwater runoff into local waterways during precipitation events. Adding 
built infrastructure to deal with the runoff would be a costly endeavor that would not benefit the urban ecosystem. To mitigate this issue, the New York City Department of Environmental Protection (DEP) released NYC Green Infrastructure Plan: A Sustainable Strategy for Clean Waterways, a formal plan for increasing green infrastructure, which details where water falls so that it may percolate through the soil or be saved for later use (DEP 2010).

Community gardens, however, were not included in this plan. This is in contrast to other municipalities across the country that value community gardens and urban agriculture as important contributions to green infrastructure in their cities (Wasatch Front Regional Council 2012, SEMCOG 2014). The US Environmental Protection Agency (EPA) lists community gardens as green infrastructure with additional ecosystem services such as space for recreation and connecting with nature (EPA 2014). The goal of this thesis is therefore to evaluate community gardens as green infrastructure by comparing the stormwater runoff rates of urban vacant lots, community gardens, and residential development in New York City. By measuring how much stormwater is retained by community gardens in comparison to other land uses, this thesis can contribute to the body of knowledge around community gardens and urban agriculture as types of green infrastructure, informing future iterations of DEP's Green Infrastructure Plan and similar initiatives both in New York City and around the country. 


\section{State of Cities}

The world's population is increasing at a rapid pace, leading to increased demand for natural resources. Land is altered for agriculture, mining, urban development, and other uses, leading to worldwide environmental degradation (Goldman and Tallis 2009). At the same time, we have entered a new phase of urbanization, where more than half of world's inhabitants currently live in cities (United Nations 2013). Yet cities only cover 3\% of the "terrestrial surface" of the planet (Millennium Ecosystem Assessment 2005). Cities are better connected than ever before, sharing and influencing culture, technology, policy, business, and more, creating a new class of global cities (Sassen 2005), and many are engaged in efforts to improve their sustainability (ICLEI 2015).

Urban development leads to heavy burdens on the environment. Wide expanses of impervious surfaces - asphalt, buildings, concrete plazas, etc. - prevent precipitation from re-entering the aquifers below (Yang and Zhang 2011). The soil that does remain open is often compacted and contaminated with heavy metals, diminishing the types and quality of life that can be sustained in it, and thus also the natural water filtering capabilities of soil (EPA 2011). These impacts can lead to flash flooding, and stormwater often ends up overflowing into nearby waterways, carrying raw sewage, trash, industrial wastewater, household chemicals, and other contaminants into our waterways with it (EPA 2014b).

This same presence of the built urban environment also contributes to increased local temperatures, known as the urban heat island effect (Taha 1997, Rosenzweig et al. 2006). Increased local temperatures lead to higher rates of air conditioning use, and therefore energy consumption and carbon emissions (Rosenfeld et al. 1995). Urban heat islands are 
in effect year-round, but impacts on residents are most pronounced in the summer, when excessive temperatures can lead to increased rates of heat-related illnesses, air pollution, and death (Rosenzweig et al. 2006). In New York City, nighttime temperatures during the summer are an average of $7.5 \mathrm{~F}$ higher than surrounding suburban and rural areas (Gedzelman et al. 2003).

Besides affecting local temperatures, large expanses of urban landscapes can also decrease the amount of habitat available for wildlife and biodiversity (Sala 2000). Migrating birds and butterflies lose their paths, soil microbiology is altered, and native flora is compromised by the presence of invasive species brought in for landscaping (Goldman and Tallis 2009). Urban development threatens biodiversity outside of cities as well, as land and natural resources are needed to feed residents, build infrastructure, and deal with waste (UN 2013). Aquatic life in the world's oceans, lakes, and rivers are considered to be some of the most at-risk due to overfishing, ocean acidification, and pollution (Goldman and Tallis 2009). All of the world's ecosystems rely on biodiversity to maintain air quality and water quality, produce flowers and seed, suppress disease, etc., and yet $12 \%-52 \%$ of known species are threatened with extinction (Millenium Ecosystem Assessment 2005).

In response, city governments across the globe are increasing the amount of green space they maintain to increase habitat for biodiversity, lessen the effects of the urban heat island effect, reduce pollution of the air and waterways, and mitigate and adapt to climate change (Kern and Alber 2008). From street trees to parks, green roofs to bioswales, cities are leveraging the benefits of green space to achieve a healthier ecosystem. Ecosystems provide services to city residents, such as water filtration and food production, and over 
the past decade there have been many contributions to the growing body of knowledge around measuring these services (Goldman and Tallis 2009).

Cities like New York City are also engaging with strategies on how to cope, adapt, and prevent the worst effects of climate change (New York City 2007). Glaciers are shrinking rapidly worldwide, threatening fresh water supplies and raising sea level (IPCC 2014). Climate change impacts the ability of cities to provide basic services and goods, including water and energy, affecting local and global economies (UN 2013). It can lead to increased flooding, especially for coastal cities, pushing cities to come up with new ways of protecting their shorelines and coping with damage to infrastructure and homes. Climate change can lead to increased public health problems through flooding, changing habitats of insects and diseases, and agricultural challenges such as drought (NPCC 2015). Combined, these issues are predicted to impose enormous financial burdens - more so if actions are not taken to mitigate climate change now (IPCC 2014, NPCC 2015).

Increased green space can also help with mitigating and adapting to climate change (Communities and Local Government 2007). Reducing summertime temperatures can decrease the city's energy load, decreasing emissions (Rosenfeld et al. 1995). Maintaining a healthy urban ecosystem can promote the absorption of stormwater, lessening the damage caused by sea level rise and large storms, and biodiversity, enhancing the resiliency of the ecosystem as a whole (Kern and Alber 2008). Often collected under the umbrella of ecosystem services, the benefits that healthy ecosystems can provide are critical to sustainable urban development. Understanding and measuring their impacts can help city governments plan for a sustainable future. 
There is a sizeable gap in the literature when it comes to the ecosystem services produced and provided by community gardens. This thesis will review the literature around measuring ecosystem services, particularly stormwater runoff for community gardens and vacant lots, on which community gardens are typically built. It will then apply multiple methodologies, both original and from the literature, for estimating stormwater runoff for community gardens, vacant lots, and residential developments for comparison in New York City. We will look at a subset of community gardens currently subject to demolition and development as a case study. Lastly, results will be compared with sustainability goals issued by the Office of the Mayor of the City of New York through various reports and initiatives to present the case for community gardens as green infrastructure. 


\section{ECOSYSTEM SERVICES}

Urban ecosystems are critical for sustaining cities. Biodiversity, stormwater retention, air pollution removal, and urban heat island effect mitigation are just a few of their important functions (McPhearson, Kremer, and Hamstead 2013). Ecosystem services are the benefits humans derive from ecosystems (Goldman and Tallis 2009), and have become a framework for studying and understanding the benefits of ecosystems, setting goals, and facilitating long-term planning and monitoring of urban ecosystems (McPherson, Kremer, and Hamstead 2013). Urban ecosystem services are particularly critical areas of study, considering half of the world population lives in cities (Haase et al. 2014). Indeed, it has been suggested that well managed urban commons and public goods can improve environmental conditions and quality of life (UN 2013, Millenium Ecosystem Assessment 2005).

While urban development imposes heavy tolls on local, regional, and global environment, urban ecosystem services help to prevent or counteract this damage. Urban ecosystem services are commonly classified into four categories: provisioning services (e.g. food and water), regulating services (e.g. stormwater regulation), habitat or supporting services (e.g. 
places for organisms to live), and cultural services (e.g. psychological benefits) (Millennium Ecosystem Assessment 2005a; Cowling et al. 2008; Kremer, Hamstead, and McPhearson 2013; Haase et al. 2014). Ecosystem services analyses are sometimes seen as expansions on more traditional biodiversity and conservation-focused frameworks (Goldman and Tallis 2009) or heavily reliant on biodiversity assessments (McPhearson, Hamstead, Kremer 2014). Given the breadth and depth of these services, the objective of ecosystem services framing is to emphasize the importance of often-overlooked environmental factors when making decisions about urban development.

Policy and planning officialy need quantitative analyses of ecosystem services for decisionmaking, and a number of methodologies, assessments, and frameworks have emerged in the past several decades (Pataki et al. 2011, Burkhard 2014). Some analyses focus on only one indicator, such as Davies et al. (2011), who quantify above-ground carbon storage. This allowed them to focus on empirical analysis of one aspect of ecosystem services. Others include multiple ecosystem services in a bundle (Van der Biest et al. 2014) or in a stack (McPhearson, Kremer, and Hamstead 2013), which respectively combine various ecosystem services with biophysical complexities and socio-ecological indicators into one index for interpreting their values. The "stacking" of ecosystem services is more often used when determining multiple payment streams for ecosystem services, where, for example, one entity or project might produce multiple ecosystem services, and can possibly receive payments for each service (Cooley and Olander 2012). Combining ecosystem services illustrates their intersectionality and may lead to new insights on how they interact. Methodologies for understanding ecosystem services both individually and grouped contribute to increased knowledge about building more sustainable cities. 


\section{Ecosystem Services in NYC}

There have been a number of studies on ecosystem services in New York City. McPhearson, Hamstead, and Kremer (2014) provide an overview of the literature and municipal assessments and policy focused on improving the urban environment. They found that the scale at which urban ecosystems services production is needed is not met by current management structures. Connolly et al. (2013) found that many of New York City's ecosystem services are produced and managed by local community organizations. Their survey of community groups working at various scales measured the contribution of environmental stewards to urban ecosystem services in New York City and found it to be increasing. Krasny et al. (2014) offers mechanisms for engaging local stewards in the measuring of ecosystem services as well - in New York City and beyond - and using the results to inform their continued work. They suggest that these practices both create green infrastructure that produces ecosystem services and constitute ecosystem services themselves, under the cultural services category. Literature on socio-ecological systems further explores the relationship between ecosystem services and local stewards and activists (Connolly et al. 2013, Krasny et al. 2014).

Several papers cite the example of New York City purchasing land along its main watershed to protect the water quality for New York City residents (Salzman 2001; Postel and Thompson 2005). Economic comparisons against building a multi-billion dollar water filtration system showed that preserving land along the aquifer would be more costefficient, with the added ecological benefits of conservation. However this policy came at 
the expense of interests upstate, who would not directly benefit from the land preservation, and is often cited as an example of the trade-offs sometimes associated with ecosystem services management.

PlaNYC and green infrastructure reports by the Department of Environmental Protection (DEP) further contribute to the body of knowledge around ecosystem services in New York City (New York City 2007, New York City 2011, DEP 2012, DEP 2013, DEP 2014). These documents assess the current status of and plan for improvements upon environmental initiatives across the city. PlaNYC, recently updated as OneNYC (New York City 2015), set the stage for comprehensive municipal urban sustainability plans nationwide when it was first published in 2007. Produced by the Office of the Mayor of New York City, PlaNYC includes the current status, future projections, and sustainability plans for population growth, housing, climate change, open green space, water management, energy use, and more (New York City 2007).

PlaNYC includes over 100 initiatives to achieve goals such as ensuring every New York City resident lives within a ten minute walk from a park and a citywide reduction in greenhouse gas emissions of 30\% over 2005 levels (New York City 2011). Meanwhile, the DEP Green Infrastructure reports have elaborated on PlaNYC's goals for ecosystem services and implemented plans for stormwater runoff reduction, improved air quality, and greener streets (DEP 2010, DEP 2012, DEP 2013, DEP 2014). PlaNYC (2011) and OneNYC (2015) both mention supporting community gardens and urban agriculture as part of their implementation plans, but the DEP Green Infrastructure reports to do not, aside from one 
grant awarded to a community garden privately managed by the New York Restoration Project to install permeable pavers.

\section{Ecosystem Services of Vacant Lots}

Vacant lots can be defined in many ways. On a broad level, a vacant lot can be defined as land that is unoccupied. Often land is vacant because an owner is holding on to it as an investment (Alexander and Powell 2011) or the municipality has no plans yet for use. New York City holds vacant land under many of its agencies, including Housing Preservation and Development (HPD) and Department of Citywide Administrative Services (DCAS). In total, $10 \%$ of New York City's land is classified as vacant (Garvin, Cannuscio, and Branas 2013) nearly 30,000 parcels (McPhearson, Kremer, and Hamstead 2013).

In all five boroughs, residents are familiar with the endless fences sporting barbed wire, overgrown weeds, and trash. The negative impacts of vacant land are well documented, and include decreased property values, safety, and community cohesion, and increased dumping, drug use, and rats (Branas et al. 2011; Kremer, Hamstead, and McPherson 2013; Garvin, Cannuscio, and Branas 2013). City residents have been advocating for better use of vacant lots for more than a century - suggesting they would be more productive as gardens, playgrounds, or other recreational spaces (Speirs, Lindsay, and Kirkbridge 1898; Curtis 1915). In many cases, lots currently listed as "vacant" in New York City's inventory are actually in use - sometimes in ways that decrease their ecological value, such as parking lots, and sometimes in ways that increase their ecological value, such as community gardens (Kremer, Hamstead, and McPherson 2013). 
While mired in negative impacts, fallow vacant land may also provide ecosystem services through stormwater retention and habitat provision (Yadav, Duckworth, and Grewal 2012; McPherson, Kremer, and Hamstead 2013). Yadav, Duckworth, and Grewal (2012) found that vacant lots had higher rates of biocontrol activity than community gardens, meaning there were healthier populations of predatory insects, mostly ants, in vacant lots as compared to community gardens. They hypothesize that this was probably due to the coverage of plant matter in vacant lots - community gardens have more heterogeneity in plant type, but it tends to be planted in patches, whereas vacant lots have more consistent coverage of weedy, grassy plants, ideal for the biocontrol activity they were measuring. Community gardens, however, had higher rates of microbial predators, likely due to the higher levels of organic matter and moisture.

McPhearson, Kremer, and Hamstead (2013) estimated the value of twelve ecosystem services for vacant lots in New York City, including carbon sequestration and storage, air pollution removal, local temperature regulation, stormwater runoff mitigation, food production, habitat, and social indicators. They found that vacant lots retain a mean of $37 \%$ of the stormwater from a 5 " rain event, and that $59-74 \%$ of the land surface was green space or bare earth, providing habitat for biodiversity. Mapping vacant lots and social indicators, they found that vacant lots existed in areas with higher need of green space areas with high population density and low income (Figure 1). Their map of these areas of high need mirrors the map of community gardens, perhaps indicating a direct response by residents to a need for ecosystem services. 


\section{Social-Ecological Cluster Analysis}
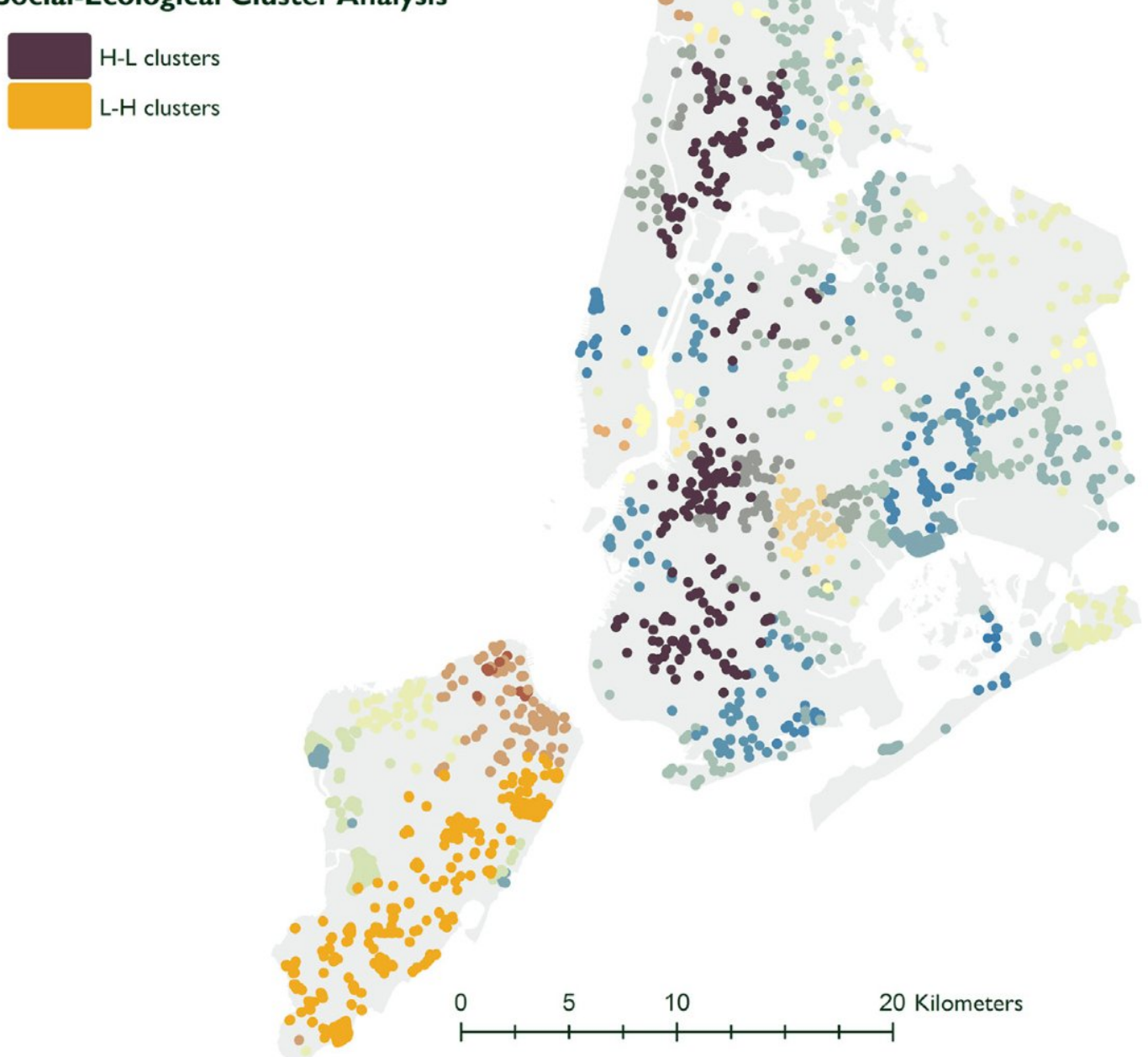

Figure 1: Figure 6C from McPherson, Kremer, and Hamstead (2013). H-L clusters represent areas of high social need and low ecological value. These areas are thus identified as priority areas for improved ecosystem services.

While urban vacant lots can sustain plant life, the soil is often compacted and not very effective for stormwater mitigation (Yang and Zhang 2011; Meyers et al. 2014). Due to its compromised nature, compacted urban soil loses its ability to filter pollutants from the water. Community gardens, urban agriculture, and other greening initiatives can help rehabilitate the soil to infiltrate more stormwater (Branas et al. 2012, EPA 2011, Meyers et 
al. 2014). Measuring the provision of ecosystem services by community gardens will help us understand the role these spaces play in urban sustainability.

\section{Ecosystem Services of Community Gardens}

The growing ecosystems services literature provides a solid framework for situating the environmental benefits of community gardens. Lin et al. (2015) found in their survey of urban agriculture ecosystem services literature that "varied vegetative structure, increased native plant diversity, and reduction of urban impervious surfaces are key features of urban agriculture systems that contribute significantly to urban biodiversity and provide important ecosystem services such as pollination, pest control, and climate resilience." With a focus on how structured vegetation contributes to biodiversity, Lin et al. (2015) approaches urban agriculture ecosystem services from the perspectives of pollination, pest control, and climate control. Andersson, Barthel, and Ahrne (2007) corroborate Lin et al.'s results, finding that community gardeners produce more biodiversity than managers of parks and cemeteries in Stockholm, Sweden.

In New York City, studies have examined food production, rainwater harvesting, land use, composting, and organizational partnerships in community gardens (Gittleman, Librizzi, and Stone 2010; Gittleman, Jordan, and Brelsford 2012) and the increase in property values that community gardens bring to their blocks (Voicu and Been 2008). Soil organic matter is higher in community gardens than vacant lots due to the addition of compost, wood chips, and other soil amendments (Dunn 2010; Yadav, Duckworth, and Grewal 2012), contributing to increased carbon sequestration and stormwater runoff mitigation. The 
addition of compost and wood chip mulch create more porous soil, allowing air and water to filter through. They also attract beneficial soil microbes and burrowing insects such as ants and worms (Yadav, Duckworth, and Grewal 2012). Trees planted by gardeners soak up stormwater, and rainwater harvesting prevents stormwater from nearby rooftops from entering the sewer system.

Meyers et al. (2014) measured the quantity and quality of stormwater runoff from community gardens and rain gardens in Chicago, using runoff from nearby rooftops as a control, as well as the reduction in municipal water needs by gardens that use rainwater harvesting systems. They found that the community garden they studied would reduce annual runoff by $73 \%$ compared to a residential development. Maintaining a rainwater harvesting system would decrease municipal water usage by $25 \%$ while retaining stormwater that would otherwise have been runoff. Extrapolated to a citywide level, the data show that community gardens in Chicago make a significant contribution to the mitigation of stormwater runoff.

Community gardens also produce cultural ecosystem services. As community-managed spaces, they rely on participation and civic engagement, and constitute the visions, needs, and cultures of diverse communities (Eizenberg 2012). Engagement with community gardens has been shown to have positive impacts on health, both physical and mental, through food production and access to green space (Wakefield et al. 2007; George 2013; Zick et al. 2013; Alaimo 2008). These services are crucial to quality of life and can further amplify the benefits ecosystem services offer to humans (Millenium Ecosystem Assessment 2005). 


\section{STUDY AREA}

New York City is an ideal location for studying the ecosystem services of community gardens. With over eight million residents, New York City is the largest city in the United States, and contains hundreds of community gardens managed by over 20,000 community gardeners (GreenThumb 2014). New York City also experiences high rates of many of the burdens placed on ecosystems by urban development. Situated on the coast and on islands, the five boroughs have a total of 520 miles of coastline, making it particularly vulnerable to sea level rise (New York City 2011). New York City is already feeling the impacts of climate change, with increased storm intensity leading to storms like Superstorm Sandy in 2013. With sea levels rising, this means increased flooding for much of the City. In addition, mean annual precipitation has increased eight inches between 1900 and 2013 (NPCC 2015), adding increased burden to the City's already over-taxed sewer system. The New York City Panel on Climate Change (NPCC) predicts that mean annual precipitation will continue to increase $4-11 \%$ by the 2050 s and $5-13 \%$ by the 2080 s (NPCC 2015 ).

Average temperatures in New York City could rise by as many as three degrees Fahrenheit in by 2030 (New York City 2011) and 4.1-5.7 degrees by the 2050s (NPCC 2015). 
Exacerbated by the urban heat island effect, increased temperatures threaten vulnerable populations with increased public health risks and death rates (NPCC 2015). Green space can help mitigate the urban heat island effect through shading and evapotranspiration.

One of the targets listed in PlaNYC is to ensure that all New Yorkers live within a 10-minute walk from a park (New York City 2011). Part of achieving this goal is to "target high-impact projects in the neighborhoods with the greatest open space needs," including "community gardens and urban agriculture opportunities." The report pledges to increase GreenThumb community garden volunteers by $25 \%$ and promises to "take a full inventory of municipal land and identify properties that could be suitable for urban agriculture." They also aim to "review existing regulations and laws to identify and remove unnecessary barriers to the creation of community gardens and urban farms," but don't mention the legal support and preservation of existing community gardens.

This is a large and conspicuous oversight, considering New York City has a history of removing active, thriving community gardens. Today there are over 500 publicly accessible community gardens, over 400 school gardens, and nearly 700 gardens on NYC Housing Authority property (Design Trust for Public Space 2012, GrowNYC 2014). In addition, there are dozens of urban farms growing commercially on rooftops and on the ground (Design Trust for Public Space 2012). Interest in urban agriculture and community gardens is on the rise across the five boroughs, for reasons ranging from food security to environmental education to stormwater mitigation. 


\section{Community Gardens in New York City}

Community gardens are often defined as land gardened collectively, and this can take on many forms: a collective garden in a private housing development, a garden managed by a non-profit, a school garden, or a publicly accessible garden managed by local residents on public land (Wakefield et al. 2007, Eizenberg 2012). While all types of community garden exist in New York City, this thesis will focus on the latter definition, as these are highly affected by decisions about public land use and open green space. Community gardens, as heterogeneous public spaces managed by volunteers, stand in contrast to urban agriculture, a growing trend in cities worldwide (Mees and Stone 2012). Urban agriculture refers to all types of food production in cities, including fruits, vegetables, and livestock (Martellozzo et al. 2014). These activies can take place in backyards, rooftop farms, commercial urban farms, and community gardens, although community gardens do not always include urban agriculture (Mees and Stone 2012). Those that do grow food are also not always interested in maximizing the space devoted to food production, as urban farms are - a few food-producing raised beds might complement social gathering spaces, ornamental gardens, and other uses (Gittleman, Librizzi, and Stone 2010; Mees and Stone 2012). This thesis will consider urban agriculture as a land use within community gardens.

The modern community gardening movement began in the 1960s and 1970s during widespread urban disinvestment in cities across the Northeastern United States (Mees and Stone 2012). Federally funded urban renewal projects justified the demolition of entire city 
blocks (Mogilevich 2014). During this time and continuing through the present, community gardens were often built on vacant plots of land that had been abandoned by their owners as the city crumbled (Schmelzkopf 1995; Nemore 1998; Schukoske 2000; Smith and Kurtz 2003; Mees and Stone 2012). During the 1970s and 1980s, municipal disinvestment combined with white flight and calculated fires left a blighted neighborhood with countless vacant lots that became sites for dumping and dangerous activity. Steeped in racism and classism, fires and disinvestment changed the landscape of neighborhoods across the city, as well as the peoples' relationship to those spaces. Joe Flood, in his New York City-based book The Fires, quotes a "high-ranking mayoral aide" in the 1970s about the fires and how the city hadn't done anything to stop them, but had, in fact, encouraged the destruction with all the cuts: “Well, you can always look on the bright side,' the aid had said. 'The city got rid of a million and a half undesirables," (Flood 2010). Displacement, fueled by racist policies, led to a cycle of disinvestment in low-income neighborhoods of color.

At the same time, supermarkets were leaving the city, following wealth into the suburbs. The processes and changes that limited food access created a food gap, where, in a country of surplus, many communities were (and still are) food insecure, a condition where people regularly run out of food or simply don't know where their next meal will come from (Winne 2008). Unequal access to food in urban areas is well documented (Anderson 1999; Campbell 2004; Clifton 2004; Pothukuchi 2004). Since many low-income urban neighborhoods lack large supermarkets, which tend to offer lower prices and wider selection, families who receive Supplemental Nutrition Access Program (SNAP) benefits and rely on small stores for their grocery needs are likely to suffer the greatest shortfalls 
when attempting to purchase a nutritious diet (C-SNAP 2008). People who live in areas without large supermarkets that carry affordable food tend to have less income and fewer healthy food options, which in turn contributes to high obesity rates and diet-related illness such as diabetes (Winne 2008).

The modern community gardening movement differs from the gardens of the past. During both World Wars, citizens planted victory gardens so produce and labor from the rural US agriculture sector could be utilized in the war effort. During the Great Depression, families could apply for plots in subsistence gardens as a means to create jobs and increase food security. Before that, in the 1890s, vacant lots were allotted to unemployed laborers to do the same, and school gardens were built at schools all over the country (Speirs, Lindsay, and Kirkbride 1898). Gardens reappeared in the 1970s, particularly in poor neighborhoods of color, often built as acts of resistance to urban decline and disinvestment, and to provide resources to address inflation, express a new environmental ethic, and reconnect neighbors during a time of social unrest (Saldivar-Tanaka and Krasny 2004, Lawson 2005).

In New York, the Green Guerillas were established in 1973 to start gardens on vacant land and received their first lease for a community garden from the city a year later (Lawson 2005). Operation GreenThumb was formed a few years later under the Department of Parks and Recreation to legitimize land agreements with the City (Mees and Stone 2012). Still in operation today, GreenThumb issues land-use licenses to gardening groups, as well as resources such as compost, lumber, and tools. While taking over a vacant lot and planting a garden might have seemed a small gesture in a neighborhood dealing with crime, drugs, and large-scale disinvestment, many considered it a pivotal first step towards 
community revitalization (Lawson 2005). Community gardens took root in many neighborhoods, and gardeners have spent more than thirty years creating a mosaic of green in spaces that were once havens for prostitution, drug use, abandoned buildings, and litter (Smith and Kurtz 2003).

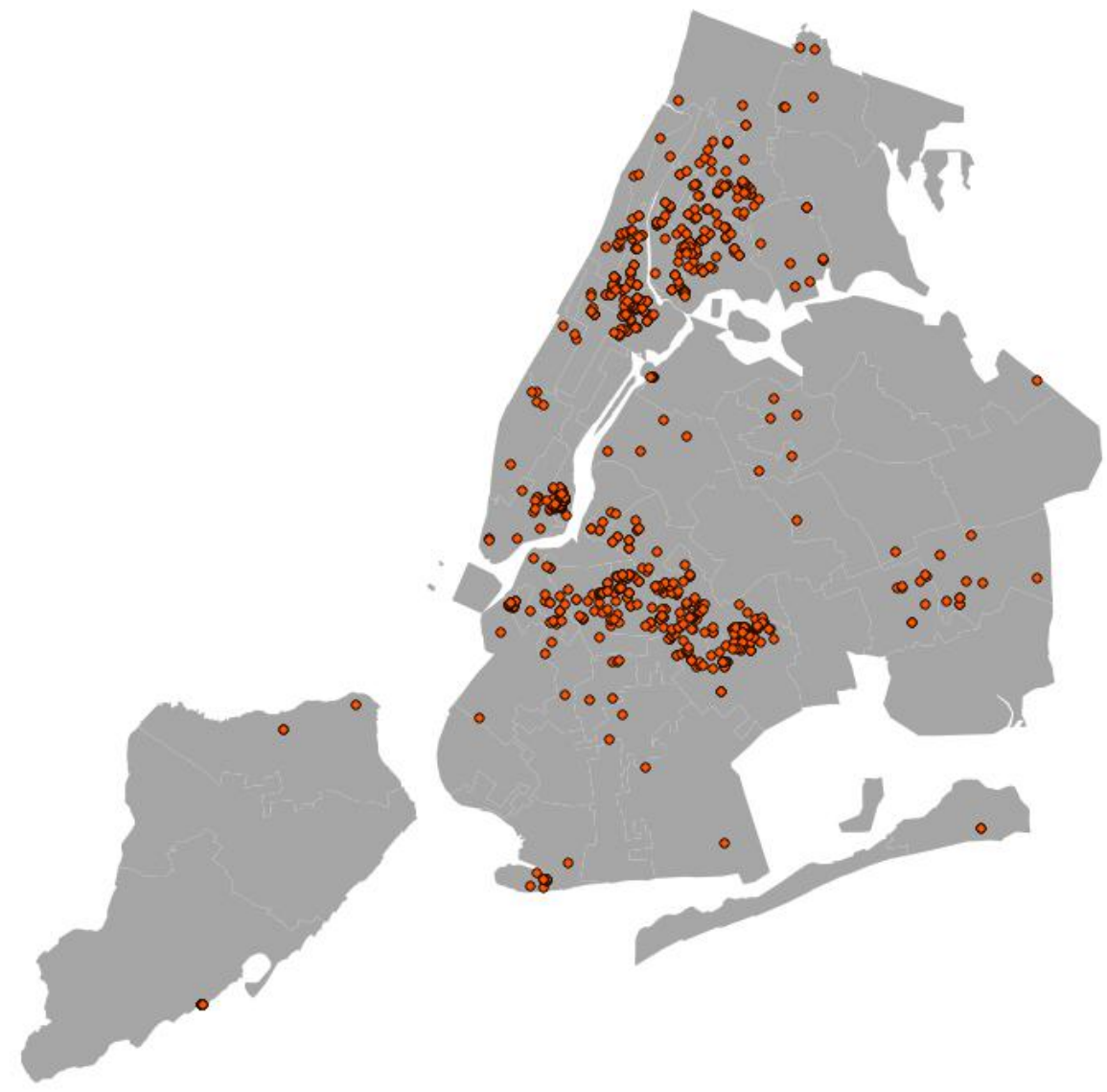

Figure 2: Community gardens in New York City (GrowNYC 2015)

Today, there are over 500 community gardens across the city that allow individuals and families to grow food and green space for themselves and for their community (Figure 2). They often also include social spaces such as seating areas, grills, stages, and artwork made by local artists. Through food and ever-changing memberships, community gardens "reflect 
the city's shifting cultural landscape" (Baker 2004). A wide variety of activities take place in community gardens such as events, political advocacy meetings, and social activities like games and barbeques (Gittleman, Librizzi, and Stone 2010). In addition, these layered benefits come at no cost to the City (Voicu and Been 2008) - the gardeners are volunteers, and support comes from local non-profits or GreenThumb, which up until 2014 was funded from federal Community Development Block Grants.

Community gardens can anchor a neighborhood, yet most New York City gardens still lack long-term land tenure, specifically the nearly 300 gardens on city-owned land. These sites in particular are periodically pitted against other land uses like affordable housing, despite the fact that they've been empirically shown to increase local property values and generate a significant amount of tax revenue from property taxes from nearby residential lots (Voicu and Been 2008, Lin, Philpot, and Jha 2015). Voicu and Been (2008) found that the 636 community (and school) gardens in New York City that they studied may generate $\$ 503$ million (2003 dollars) in property tax revenue from residences within 1,000 feet of a garden over a 20-year period, or $\$ 790,880$ per garden, not including the costs incurred by the City in developing the garden. This is $\$ 1,014,900$ in 2015 dollars. Applied to the 537 community gardens (excluding school gardens) in this study, we get an estimated $\$ 545,001,300$ in tax revenue over 20 years. Consequentially, when a community garden raises nearby property values and makes a neighborhood more desirable, they may be inadvertently contributing to gentrification, which in turn increases development pressure in and around the garden (Schmelzkopf 1995, Tortorello 2015). 
In the late nineties, then-Mayor Rudy Giuliani attempted to auction many of the City's community gardens (Mees and Stone 2012). Residents fought back and won a settlement that saved many of the gardens (NYCCGC 2010). More recently, Mayor de Blasio unleashed an affordable housing plan and a Request for Qualifications that includes 17 community gardens among the plots of land available for development. At the time of this writing, community gardeners are currently organizing around this issue, advocating for both housing and gardens.

Some of the council members in the districts with threatened gardens at first assumed this was an administrative error (Tortorello 2015). In New York City's land use map, issued by the Department of City Planning, the land occupied by community gardens is labeled as "vacant," even if a garden has been there for 40 years. Yet New York City is home to over 500 community gardens, over $50 \%$ of which are on public land (Gittleman, Librizzi, and Stone 2010). They cover 5,283,418 square feet (121.3 acres), less than one sixth the size of Central Park. New York City has no de facto law protecting community gardens on public land, and despite decades of service to neighborhoods, many continue to find themselves without legal standing.

In a survey of New York State community gardens, Armstrong (2000) found that community gardens increase property values in the neighborhood, which may lead to sales that in turn lead to the destruction of the gardens. Armstrong also marks this as one of the reasons for gardeners losing city-owned land. Yet in this most recent case, lots are being sold to developers for $\$ 1$, in neighborhoods that sorely need more green space (Tortorello 2015). NYC Council members with threatened gardens in their districts attempted to find 
out why these particular gardens were on the list and were met with no answer. In a statement made to rally attendees protesting the inclusion of 17 community gardens on a Request for Qualifications by Housing Preservation and Development seeking proposals for affordable housing, Council member Robert Cornegy stated,

There was a reason I didn't speak out immediately following HPD's publication of the list of development properties in January, even though there were more gardens listed in my district than any other. I wanted to take the time to try and understand HPD's decision making. There's no doubt that the $36^{\text {th }}$ district needs more truly affordable housing. And it's a good thing that HPD is acting on it commitment to construct a small number of units for affordable home ownership. I was open to an explanation that demonstrated the absolute necessity of using the garden sites. I asked for a full explanation, but that's not what I've received. Specifically, I asked that HPD share the objective criteria used to determine which vacant lots were appropriate for inclusion in this RFP. Shockingly, they have shared NO criteria. And I asked that HPD provide me with a list of all the city-owned properties in the district of every size, to show that these much loved garden sites were somehow uniquely appropriate. Again, HPD chose to share nothing. (596acres.org 2015)

In the absence of evidence of a decision-making process, gardeners, residents, and representatives are left to speculate. However these spaces have value for more than just the nearby residents. The NYC Department of Sanitation (DSNY) recognizes community gardens for their work composting food scraps and leaf litter, reducing the volume of waste they have to manage. After receiving a letter from Councilmember Antonio Reynoso, Chair of the Committee on Sanitation and Solid Waste Management, regarding the affordable housing proposal's impact on community compost initiatives, Kathryn Garcia, Commissioner of DSNY, acknowledged the role community gardens play in greening the city:

The success of our mutually shared goal to develop a long-term strategy to divert organic material from the waste stream depends on expanding the City's composting infrastructure and creating convenient locations for New Yorkers to drop off their food scraps. Community-based gardens that engage in small-scale composting are an important part of this infrastructure, and contribute beneficially 
to a greener New York City. I am also mindful, though, of the Mayor's ambitious goal to build much-needed affordable housing in the City, and where those needs are most critical, it may be necessary for some gardens to cease operating to make way for affordable homes that also greatly benefit communities in a demonstrable way. I agree that long-term planning for organic waste infrastructure in communities across the City should be taken into consideration while carefully balanced against the critical need to construct and maintain affordable housing. (Garcia 2015)

This letter acknowledges both the tension between community gardens and other land uses and the potential for community gardens to serve tangible needs for the City. Nearly a third of New York City waste is organic waste (Garcia 2014), and community compost initiatives in community gardens help shoulder the burden, often at no cost other than the in-kind use of vacant land. In order to support these initiatives and reap the benefits of local composting initiatives, the City needs to coordinate priorities before making land use decisions.

Another critical service that community gardens provide is stormwater runoff mitigation, which in many other cities puts them under the umbrella of green infrastructure (Meyers et al. 2014). Green infrastructure decreases and/or slows the quantity and rate of stormwater entering the sewer system by allowing rainfall to percolate through the ground where it falls or otherwise detaining it. Community gardens offer that service by increasing the amount of stormwater retained in the ground as compared to that retained by a vacant lot or residential development. In addition, at least 132 community gardens in New York City use rainwater-harvesting systems with a total holding capacity of over one million gallons (GrowNYC 2015b).

Literature that quantifies runoff (and ecosystem services in general) for community gardens is scarce (Freshwater Society 2013). Meyers' (2014) study for Openlands in 
Chicago, Illinois, installed stormwater runoff collection devices on a variety of garden types, including a rain garden and a community garden, to measure the quantity and quality of the runoff. They compared the runoff volume from the Lawrence Community Garden with the runoff volume from the roof of a nearby building and found that the community garden prevented almost four times the rain from becoming runoff than the building. Other studies use proxy values from the literature to estimate runoff for gardens in general, including community gardens (Center for Neighborhood Technology 2007).

\section{Green Infrastructure}

Several studies include community gardens as green infrastructure (Freshwater Society 2013; Krasny et al. 2013; Andersson et al. 2014), and the few studies that estimate or quantify stormwater runoff for community gardens illustrate their value in maintaining a healthy urban ecosystem (Edmonson et al. 2014; Meyers et al. 2014). In a rural environment, rainwater percolates through the soil and replenishes the aquifer beneath it. Cities, however, are covered with impervious surfaces that prevent rainwater from entering the soil directly. As a result, much of it becomes runoff, causing flash flooding and overwhelming water treatment centers. New York City's sewer system relies on combined sewer overflows (CSOs) that discharge a mixture of untreated sewage and stormwater runoff directly into nearby waterways when it rains (DEP 2010). CSO events can occur after as little as one tenth of an inch of rain (New York City 2007). Over the course of a year, approximately 30 billion gallons of wastewater are discharged into New York City waterways through CSOs (Strickland 2012). Historically, cities such as New York City have 
relied on wastewater treatment facilities to manage storm water, but with increased development such facilities have been over capacity for decades. Many older cities, particularly in the Northeast, rely on CSOs to discharge excess wastewater (New York City 2007).

CSOs heavily pollute waterways with pathogens from raw sewage and toxins from runoff and industry waste. The inability to safely manage wastewater has been linked to the loss of oysters and other wildlife in the New York City harbor at the start of the twentieth century, which had until then helped to filter out pollutants in the water (New York City 2007). The Gowanus Canal in Brooklyn has been designated a Superfund site by the EPA, acknowledging its excessive toxicity. With miles of waterfront property, New York City has a strong interest in cleaning up the waterways to make them accessible to residents for recreation and development once again (DEP 2010). Decreasing CSO output is also a federal mandate issued by the EPA under the Clean Water Act for many cities across the country, NYC included (Salzman 2001; Postel and Thompson 2005).

Increased precipitation and storm intensity are predicted for New York City in the near future (NPCC 2015), yet New York City lost 9,000 acres of vegetated land cover between 1984 and 2002, making increased green space a priority for stormwater management (New York City 2007). Relying solely on the addition of new built infrastructure to deal with the runoff, such as expanded wastewater treatment centers, would be a costly endeavor that would not benefit the urban ecosystem. As such, municipalities such as New York City are initiating plans for increasing green infrastructure. Some of these plans 
include community gardens and urban agriculture (Wasatch Front Regional Council 2012, SEMCOG 2014) and some, including New York City's, do not (DEP 2010, CMAP 2010).

Green infrastructure leverages ecosystem functions such as soil infiltration and plant evapotranspiration to reduce or slow the stormwater entering the sewer system. This provides a cost-effective way to complement the City's "grey" infrastructure, such as holding tanks, while contributing additional benefits in the form of green space. Adding vegetation to a site and using pervious materials can decrease stormwater runoff with the added benefits of decreasing local temperatures, improving air quality, sequestering carbon, and raising property values (DEP 2012).

In 2010, the New York City Department of Environmental Protection (DEP) issued the NYC Green Infrastructure Plan: A Sustainable Strategy for Clean Waterways that outlines strategies for improving the way the city deals with stormwater (DEP 2010). Since then, several successful initiatives have been put in place: Million Trees NYC, which aims to plant one million new trees across the five boroughs; a rainwater harvesting barrel give-away program; and increased numbers of Greenstreets are just a few. The 2015 progress report for this plan prioritizes several types of green infrastructure: 1) Right-of-way bioswales, which they define as "planted areas in the sidewalk that are designed to collect and manage stormwater;" 2) Stormwater Greenstreets, like bioswales but larger and in the street; 3) green roofs; 4) blue roofs, which create "temporary ponding and gradual release of stormwater; 5) rain gardens, "vegetated or landscaped depressions designed with an engineered soil layer that promotes infiltration of stormwater runoff into the underlying soil;" 6) Permeable paving, a range of materials and techniques, such as permeable pavers 
or porous concrete, which allow water to seep in between the paving materials and be absorbed into the ground;" 7) subsurface detention systems, which provide temporary stormwater storage underground, and 8) cisterns and rain barrels, which collect and store water in water-tight containers above or below ground (DEP 2015).

The NYC Green Infrastructure Plan aims to reduce CSO volumes by capturing the first inch off of $10 \%$ of New York City's impervious surfaces, which amounts to an estimated 1.5 billion gallons of water/year (DEP 2010). The plan includes some grey infrastructure as well, which another term for conventional water treatment systems with built structures such as pipes, holding tanks, and wastewater treatment plants. Combined with green infrastructure, however, New York City's wastewater system will capture more stormwater runoff than traditional grey infrastructure for an estimated $\$ 5.3$ billion over 20 years, $\$ 2.4$ billion less than grey infrastructure (Strickland 2012). Over the same period, the DEP estimates that New Yorkers will receive \$139 million-\$418 million in additional benefits through reduced energy bills, increased property values, and improved health, due to the impact green infrastructure has on other aspects of urban ecosystems (Strickland 2012). In order to meet the milestones in this plan, DEP identified Priority CSO Tributary Areas that drain to specific CSO outfalls with the highest volume and frequency of CSO events (Figure 3) (DEP 2013). 
Priority CSO Tributary Areas

$\square$ Eligible

Not Eligible

Priority
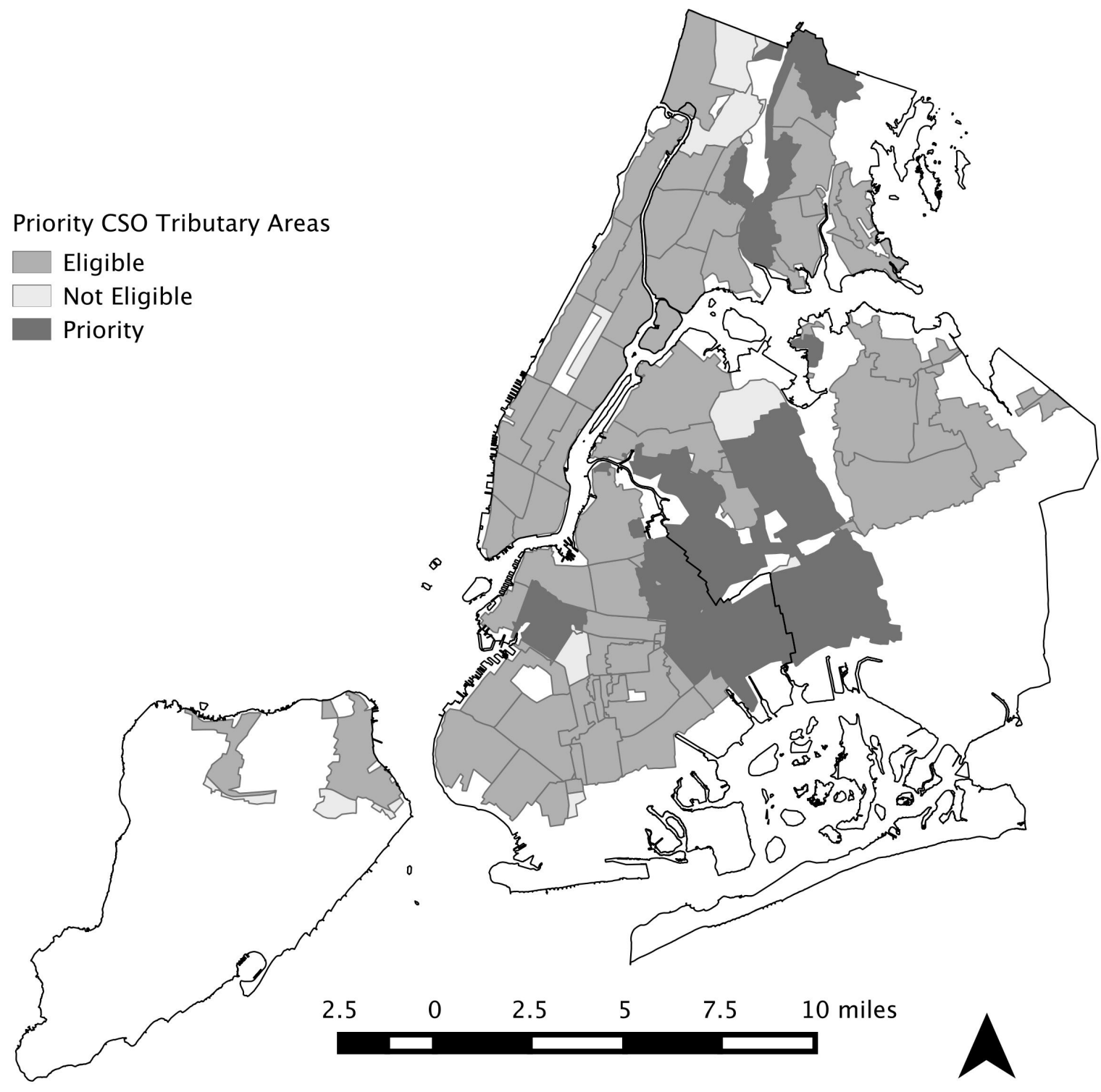

Figure 3: Priority CSO Tributary Areas Map (Claro et al. 2013)

The DEP has 2188 green infrastructure sites listed in their database (DEP 2014) (Figure 4). $80 \%$ of these are rain barrels, given away annually to NYC residents as part of the implementation of the NYC Green Infrastructure Plan. 


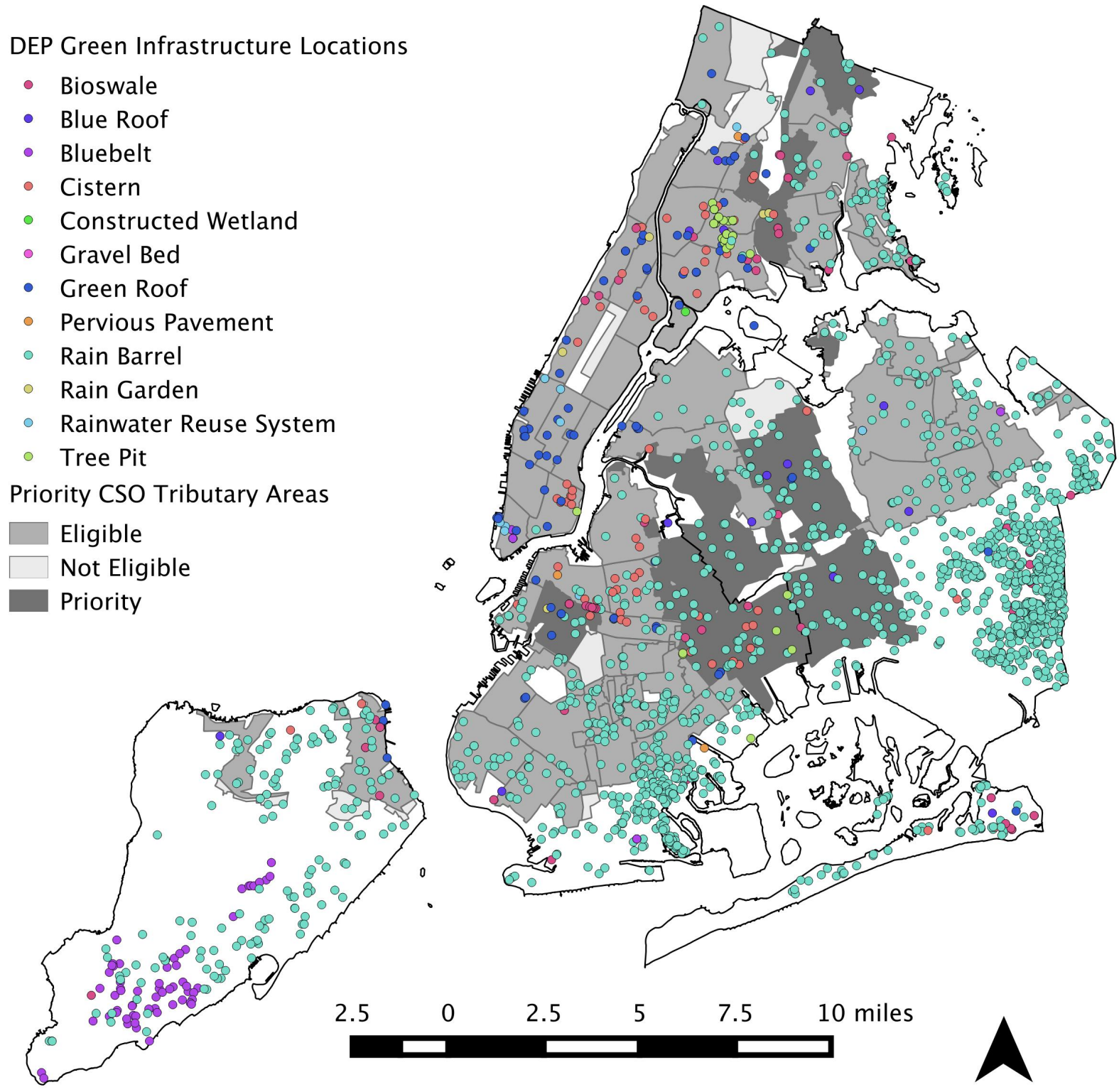

Figure 4: DEP green infrastructure locations by type

Of the 416 remaining sites, 53 are located in priority areas, 246 in eligible areas, 6 in ineligible areas, and 111 are located outside of the CSO tributary areas. This is in contrast to the presence of community gardens: of which 149 are in priority areas, 346 are in eligible areas, 7 are in ineligible areas, and 46 are elsewhere (Figure 5). 


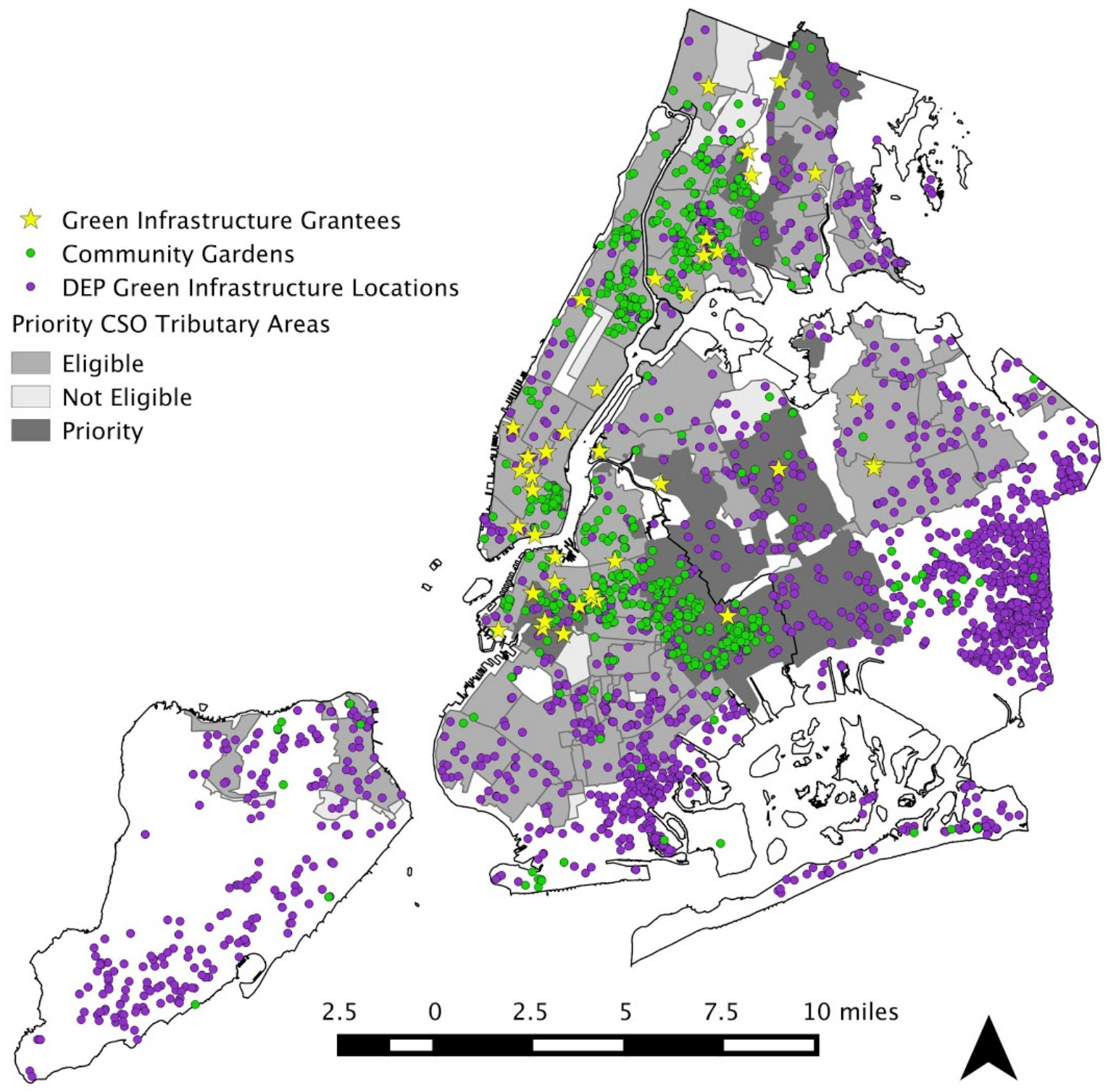

Figure 5: Community gardens and DEP green infrastructure locations

The NYC Green Infrastructure Plan includes vacant lots as one of the land uses with potential for stormwater mitigation through "rain gardens and green gardens," as well as through their grant program (DEP 2010, Table 1). If the DEP supported community gardens as green infrastructure, it could include a variety of cost-effective mechanisms for 
supporting existing and creating new community gardens to achieve its goals. In order to make the case for community gardens as green infrastructure, we need to understand what happens to rainwater when it lands on community gardens. The following section will estimate stormwater runoff for community gardens and compare the results with estimates of runoff from residential and vacant lots. 


\section{METHODS \& RESULTS}

This chapter will outline the methodology used in this study to calculate stormwater runoff for community gardens, vacant lots, and residential areas in New York City. All three of these values will be calculated for the same plots of land currently occupied by community gardens: ecosystem services provided by community gardens will be compared to the ecosystem services provided by the vacant lots that they used to be and by residential lots to which many community gardens are converted. Two different methods will be employed for estimating stormwater runoff for both community gardens and vacant lots, including methods from the literature and original methods for comparison. This will contribute to the growing body of knowledge around green infrastructure and make the case for community gardens to be considered a valuable resource in New York City.

\section{Calculating stormwater runoff volume}

This thesis will use the methodology and values included in the USDA Soil Conservation Service TR-55 report (1986), one of the most commonly used methodologies for estimating 
stormwater runoff. The TR-55 methodology identifies curve numbers (CN) that describe the proportion of runoff for a given rain event while taking into consideration land cover type, soil characteristics, and the fact that infiltration capacity of soils change over the course of a storm. Using USDA TR-55 methods, I will compare the stormwater runoff mitigation benefits of community gardens to other land uses, including vacant lot and residential development.

TR-55 calculates inches of runoff for a given precipitation event using the following formula:

$Q=\frac{\left(P-I_{a}\right)^{2}}{\left(P-I_{a}\right)+S}$

where $Q$ is runoff in inches for a $P$-inch rain event, $S$ is the potential maximum runoff after runoff begins (determined by $\mathrm{CN}$ ), and $I_{a}$ is the initial abstraction in inches. Initial abstraction $\left(I_{a}\right)$ is "all losses before runoff begins" and "includes water retained in surface depressions, water intercepted by vegetation, evaporation, and infiltration" (USDA 1986). It is related to $S$ by: $I_{a}=0.2 S$. So formula (1) can be rewritten as:

$$
Q=\frac{(P-0.2 S)^{2}}{(P+0.8 S)}
$$

where $S$ is derived from the CN by:

$S=1000 C N-10$ 
CN values used in this analysis come from Table 2.2 in TR-55 (USDA 1986, p.2-5 - 2-7) and the CNT Green Values Stormwater Calculator based on hydrologic soil group (Center for Neighborhood Technology 2007).

\section{Hydrologic Soil Group}

Analysis of the benefits of stormwater mitigation combines land cover type and soil type. Different land cover types will allow varying levels of stormwater infiltration: in forests, infiltration rates will be high, whereas on buildings, asphalt, and other impervious surfaces, stormwater will not infiltrate at all. Hydrologic soil groups represent information about soil quality and drainage. Soils are classified into four hydrologic soil groups (A, B, C, and D) according to their minimum infiltration rate (USDA 1986). Soils in hydrologic soil group A have the lowest runoff potential, while soils in hydrologic soil group D have the highest (Table 1). Hydrologic soil groups for New York City soils came from the Natural Resources Conservation Service, which releases soil data at the county level through the Soil Survey Geographic Database (SSURGO). 
Table 1: Four hydrologic soil groups as defined in USDA TR-55 (Table 3-3, 1986)

\begin{tabular}{|l|l|}
\hline $\begin{array}{l}\text { Group } \\
\text { A }\end{array}$ & $\begin{array}{l}\text { A soils have low runoff potential and high infiltration rates even when thoroughly } \\
\text { wetted. They consist chiefly of deep, well to excessively drained sand or gravel and } \\
\text { have a high rate of water transmission (greater than 0.30 in/hr). The textures of } \\
\text { these soils are typically sand, loamy sand, or sandy loam. }\end{array}$ \\
\hline $\begin{array}{l}\text { Group } \\
\text { B }\end{array}$ & $\begin{array}{l}\text { B soils have moderate infiltration rates when thoroughly wetted and consist } \\
\text { chiefly of moderately deep to deep, moderately well to well drained soils with } \\
\text { moderately fine to moderately coarse textures. These soils have a moderate rate of } \\
\text { water transmission (0.15-0.30 in/hr). The textures of these soils are typically silt } \\
\text { loam or loam. }\end{array}$ \\
\hline $\begin{array}{l}\text { Group } \\
\text { C }\end{array}$ & $\begin{array}{l}\text { C soils have low infiltration rates when thoroughly wetted and consist chiefly of } \\
\text { soils with a layer that impedes downward movement of water and soils with } \\
\text { moderately fine to fine texture. These soils have a low rate of water transmission } \\
\text { (0.05-0.15 in/hr). The texture of these soils is typically sandy clay loam. }\end{array}$ \\
\hline $\begin{array}{l}\text { Group } \\
\text { D }\end{array}$ & $\begin{array}{l}\text { D soils have high runoff potential. They have very low infiltration rates when } \\
\text { thoroughly wetted and consist chiefly of clay soils with a high swelling potential, } \\
\text { soils with a permanent high water table, soils with a claypan or clay layer at or } \\
\text { near the surface, and shallow soils over nearly impervious material. These soils } \\
\text { have a very low rate of water transmission (0-0.05 in/hr). The textures of these } \\
\text { soils are typically clay loam, silty clay loam, sandy clay, silty clay, or clay. }\end{array}$ \\
\hline
\end{tabular}

\section{Community Garden Data}

The dataset for community gardens in New York City comes from GrowNYC (2015) as part of their Open Space Greening program. It contains records that fall outside the scope of this project, including school gardens and private gardens, and contains some out-of-date records of community gardens that have been demolished. Furthermore, some of the garden footprints were incorrectly located or drawn differently than the garden's actual footprint. In many cases, the footprint was drawn to incorporate nearby buildings. The first step of this analysis was to review the dataset and remove those that do not fall under this 
project's definition of community garden, and use aerial imagery to edit incorrect garden footprints (a more extensive coverage of this "data cleaning" procedure is given in Appendix A).

Community gardens in New York City are most frequently in the $\mathrm{C}$ hydrologic group, classified by low infiltration rates (Figure 6). Amending this soil with compost may have a greater impact on runoff than those in Group A (Cogger 2005). Community gardens receive over 1,000 tons of compost and topsoil annually, improving the porosity and water holding capacity of the underlying soil (GreenThumb 2014). 


\section{Garden Hydrologic Soil Group}

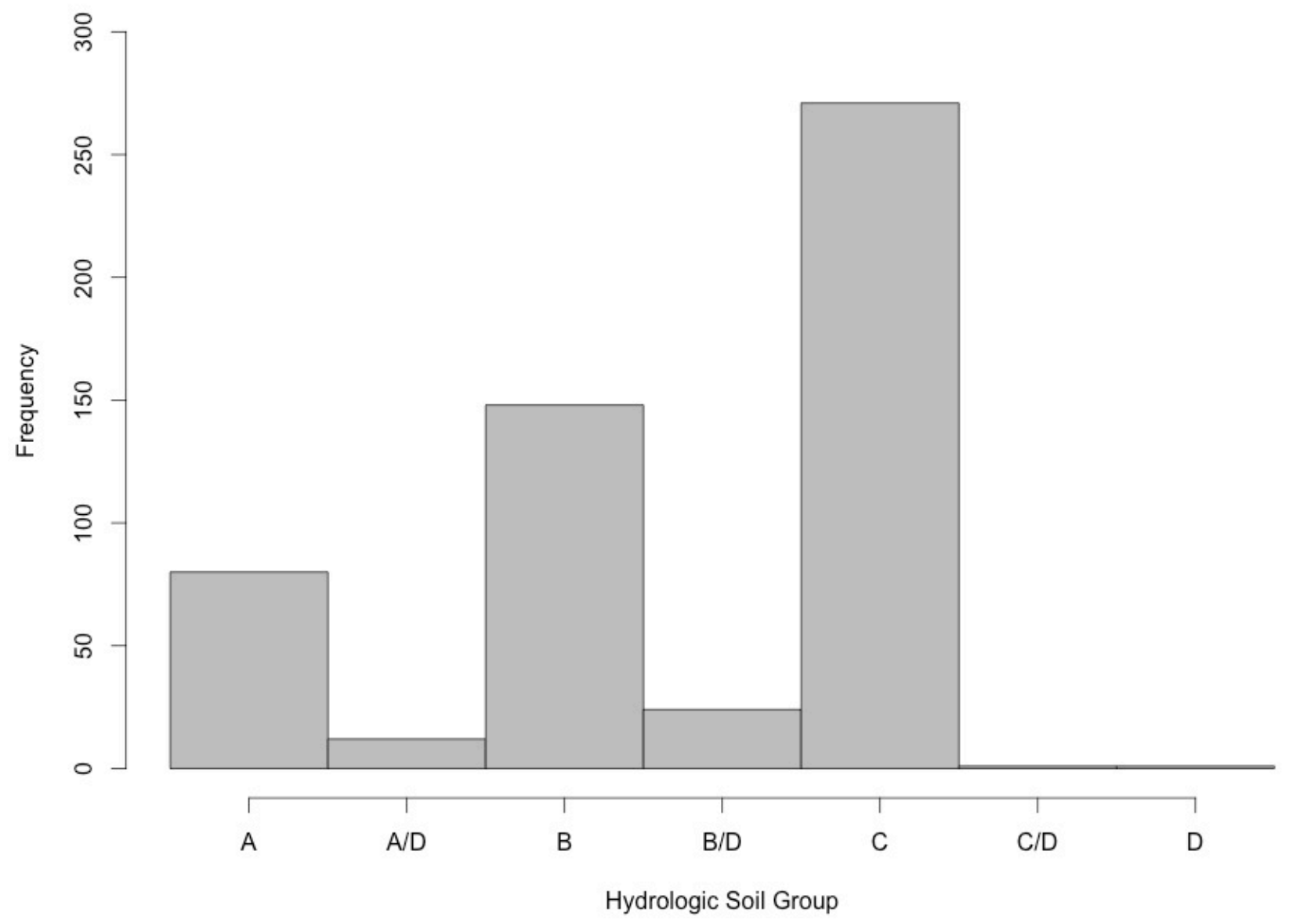

Figure 6: Community garden soil hydrologic groups. A/D, B/D, C/D include some impervious surface area (SSURGO)

\section{Joining with land cover data}

Land cover data for New York City comes from the University of Vermont Spatial Analysis Laboratory and New York City Urban Field Station (2012) at 3-foot resolution, based on 2010 LiDAR data and 2008 4-band orthoimagery. To identify land cover types for each community garden, the land cover dataset was clipped to the updated NYC Community Gardens dataset. Seven land cover classes were mapped: (1) tree canopy, (2) grass/shrub, (3) bare earth, (4) water, (5) buildings, (6) roads, and (7) other paved surfaces. Area was 
calculated for each land cover type within each community garden. Based on the computed areas, the proportion of each type of land cover was calculated and adapted to fit the TR-55 classifications: "tree canopy" and "grass/shrub" were combined to form an "open space" classification, and "buildings," "roads," and "other paved surfaces" were combined as "paved," or impervious. "Bare earth" was kept as "bare." The data were reclassified into these categories in order to calculate runoff using the TR-55 methodology (1986), following the McPhearson, Kremer, and Hamstead (2013) study on the ecosystem services of vacant lots in New York City. Because New York City has no alternative for labeling community gardens in their land use database (PLUTO), community gardens on public land are labeled as "vacant lots," and were thus likely included in past studies on vacant lots in New York City.

The proportion of "open space" and the soil hydrologic group for each lot were used to identify a curve number using Table 2.2 in TR-55 (USDA 1986) (Table 2). Curve numbers are used to compare stormwater runoff across different land cover types and are based on soil hydrologic group, plant cover, and impervious surface area. 
Table 2: Curve numbers for open space, bare soil, and paved areas (USDA 1986)

\begin{tabular}{|c|l|l|l|l|}
\cline { 2 - 6 } \multicolumn{1}{c|}{} & \multicolumn{4}{|c|}{ Hydrologic Group } \\
\hline Land Cover & A & B & C & D \\
\hline Open Space & & & & \\
\hline Poor condition (grass cover <50\%) & 68 & 79 & 86 & 89 \\
\hline Fair Conditon (grass cover 50\% to 75\%) & 49 & 69 & 79 & 84 \\
\hline Good Condition (grass cover $>75 \%)$ & 39 & 61 & 74 & 80 \\
\hline Bare soil & 77 & 86 & 91 & 94 \\
\hline Paved & 98 & 98 & 98 & 98 \\
\hline
\end{tabular}

Curve numbers were multiplied by the areas of each land cover type within each garden and divided by the total garden area to create a weighted CN value for each garden:

$C_{w}=\frac{\left[\left(C_{o} * A_{o}\right)+\left(C_{b} * A_{b}\right)+\left(C_{p} * A_{p}\right)\right.}{A_{t}}$

where $C_{w}$ is the weighted curve number $(\mathrm{CN}), C_{o}$ is the $\mathrm{CN}$ for open green space, $A_{o}$ is the area of the garden classified as open green space, $C_{b}$ is the $\mathrm{CN}$ for bare soil, $A_{b}$ is the area of the garden classified as bare soil, $C_{p}$ is the $\mathrm{CN}$ for paved surfaces, $A_{p}$ is the area of the garden classified as paved, and $A_{t}$ is the total area of the garden. Weighted CN values for these lots ranged from 39 to 98 with a mean of 79.58 .

Over the course of this process, it became clear that many of the gardens were incorrectly classified in the land cover maps. After comparing the land cover classifications with aerial photography, it became clear that for several community gardens, land cover type was 
identified as "other paved surfaces" when it should have been labeled as "tree canopy," "grass/shrub," or "bare earth" (Appendix A). Similarly, there were many community gardens with a large percentage of their land cover listed as "buildings." Reviewing aerial photography for each garden revealed that many of these gardens were either misplaced or incorrectly drawn (See Figures 7 and 8 for examples).

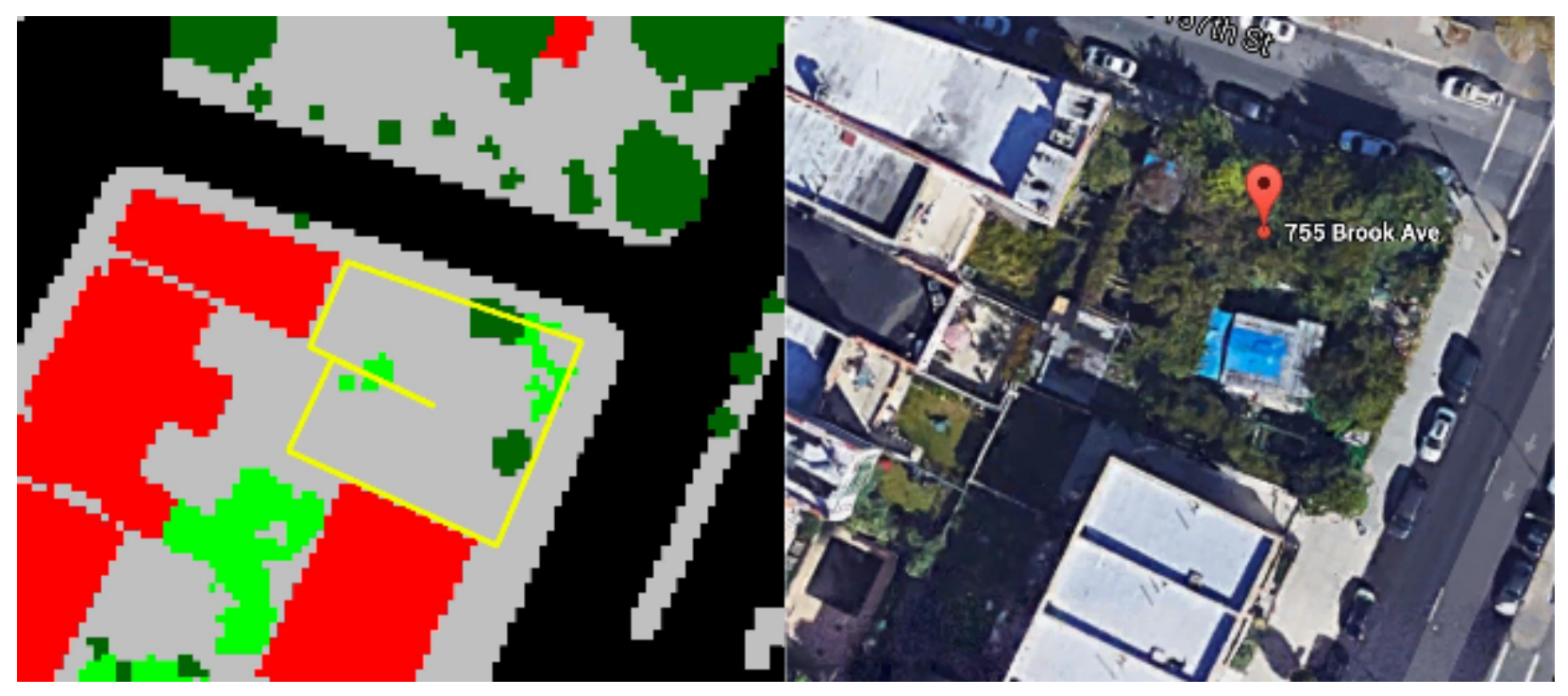

Figure 7: El Centro Rincon Criollo Community Garden in the Bronx: Incorrect land cover classification. Red denotes building, grey denotes paved area, dark green denotes tree cover, and light green denotes grass or brush cover. Clearly, much of what has been identified as pavement is actually tree cover. 


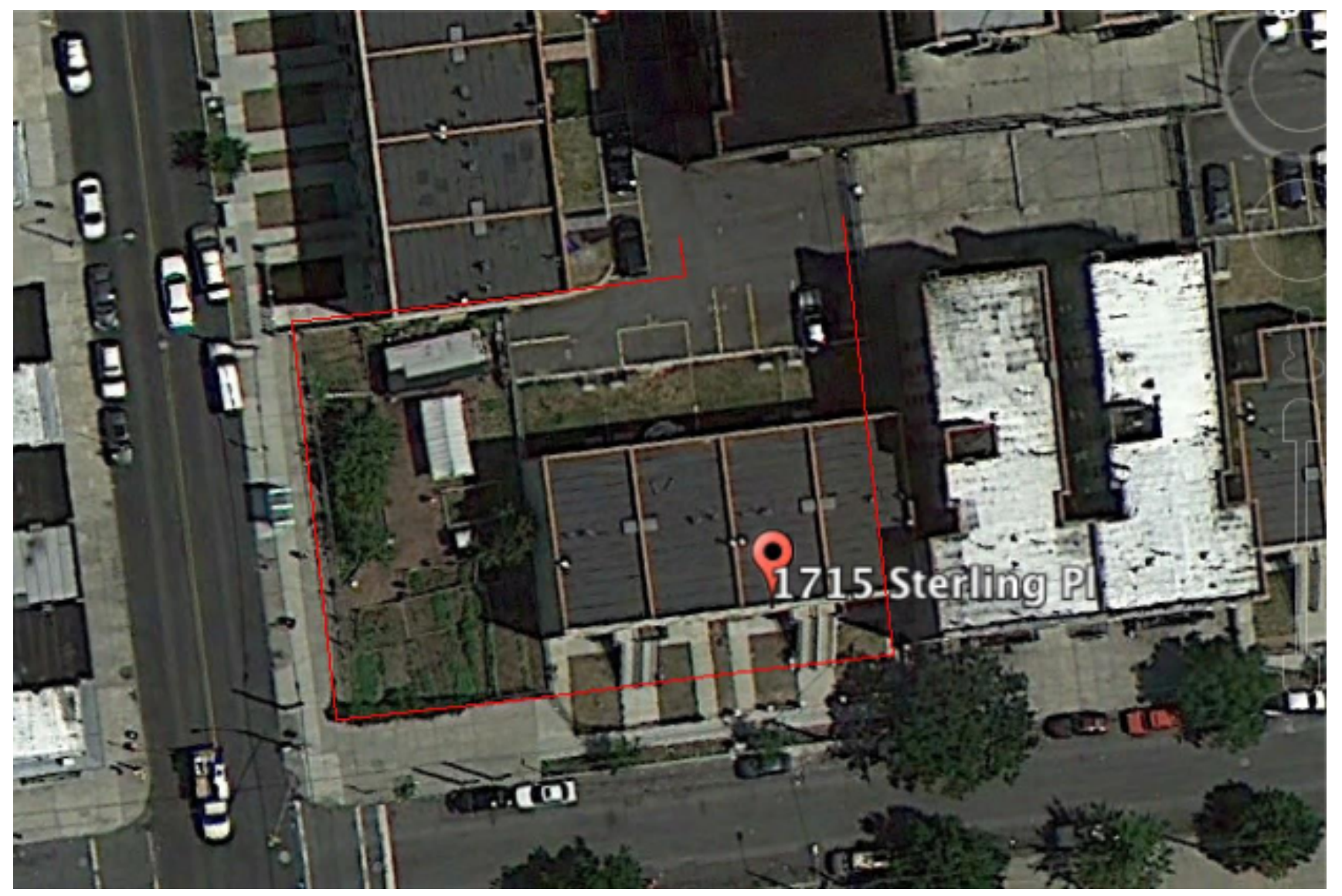

Figure 8: Sterling Community Garden, incorrect border

All garden footprints with $>25 \%$ building coverage were edited and the garden and land cover areas were recalculated. The presence of extra impervious surface means that this analysis may result in an inaccurate measure of the stormwater mitigation benefits of community gardens, so this data correction step is crucial. While every attempt was made to identify and correct all garden location errors, it is possible that errors remain. With time and resources it is likely that all such errors could be fixed; this is a potential future direction for this research, and it is hoped that the findings presented here will lead to new efforts to build and maintain accurate databases of community gardens in the New York City metro area. 
Vacant lots are some of the most heterogeneous spaces in New York City (McPhearson, Kremer, and Hamstead 2013; Tidball and Krasney 2010), and often contain paved areas and remnants of buildings. To estimate stormwater runoff, I will continue to use this land cover data (M1), and will compare the results against calculations using commonly used values from Table 2.2 in TR-55 (USDA 1986, p.2-5 - 2-7; reproduced in Table 8) for analyzing vacant lots (M2). For community gardens, I will also compare two different methods: for the first, I will utilize published data for stormwater runoff characteristics of gardens as a whole, rather than broken down by land cover type (M1). For the second, I will add urban agriculture as a land cover type to the data on vacant lots and measure the change in estimated runoff (M2).

Useful CN values for runoff from community gardens are provided by the Center for Neighborhood Technology (CNT) Green Values Stormwater Calculator, which was developed in collaboration with the US Environmental Protection Agency (EPA) Office of Wetlands, Oceans, and Watersheds, Assessment and Watershed Protection Division, NonPoint Source Branch to help planners and green infrastructure designers across the United States predict the benefits of their projects (Center for Neighborhood Technology 2009). The tool synthesizes measurements for estimating runoff reduction, carbon sequestration, energy reduction, and financial savings associated with green infrastructure. The methodology uses runoff curve numbers adapted from comparable land uses in Table 2-2 of TR-55 for each soil type (Center for Neighborhood Technology 2007). For gardens and swales, the runoff curve numbers for each soil type are in Table 3. 
Table 3: Runoff curve numbers for gardens and swales (Center for Neighborhood Technology 2007)

\begin{tabular}{|c|c|c|c|c|}
\hline Hydrologic Group & A & B & C & D \\
\hline Garden CN & 35 & 51 & 63 & 70 \\
\hline
\end{tabular}

Because New York City is considering building housing on several community gardens, I will also include stormwater runoff from residential developments. Table 2-2 in TR-55 (USDA 1986) provides the curve numbers for residential lots of $1 / 8$ acre or less listed in Table 4.

Table 4: Curve numbers for residential lots from Table 2-2 in TR-55 (USDA 1986)

\begin{tabular}{|c|c|c|c|c|}
\hline Hydrologic Group & A & B & C & D \\
\hline Residential CN & 77 & 85 & 90 & 92 \\
\hline
\end{tabular}

\section{Stormwater Runoff in Community Gardens}

\section{M1: Replicating methods from the literature}

For each community garden land parcel in NYC, three different $Q$ values (inches of runoff for a given rain event of $P$ inches) were calculated using Formula 2. The three $Q$ values were calculated using curve numbers that identify them as gardens, vacant lots, and residential developments, so that we can compare how runoff changes based on land use on the same plots of land. 
The NYC DEP 2012 Green Infrastructure Monitoring Report uses a 1.5" rain event as an example storm. Past studies have used a 5" rain event as a benchmark for a 5-10 year storm that would overwhelm New York City's water treatment system (McPhearson, Kremer, Hamstead 2013; Kremer, Hamstead, McPhearson 2015). Viewed as a range, these benchmarks can tell us how community gardens, vacant lots, and residential developments absorb and release rain (Tables $5 \& 6$ ). 

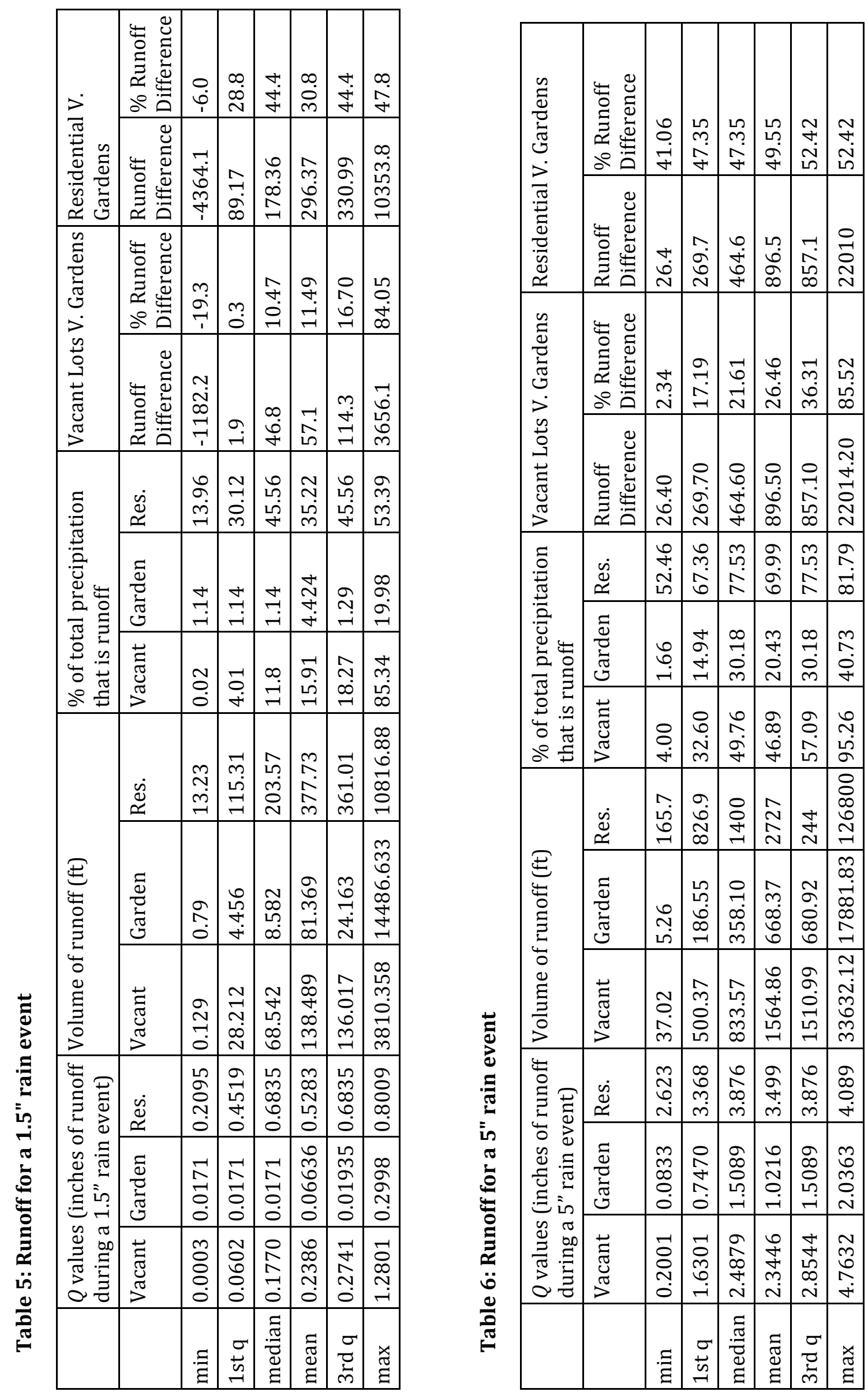
The size of the land parcel has a major impact on the total volume of runoff when calculated as a garden. The gardens in this dataset range in size from 555 sq. ft. to 579,900 sq. ft., with a median of 4,787 sq. $\mathrm{ft}$. and a mean of 9,839 sq. $\mathrm{ft}$., indicating that most of the gardens are on the smaller end (Figure 9).

\section{Community Garden Areas}

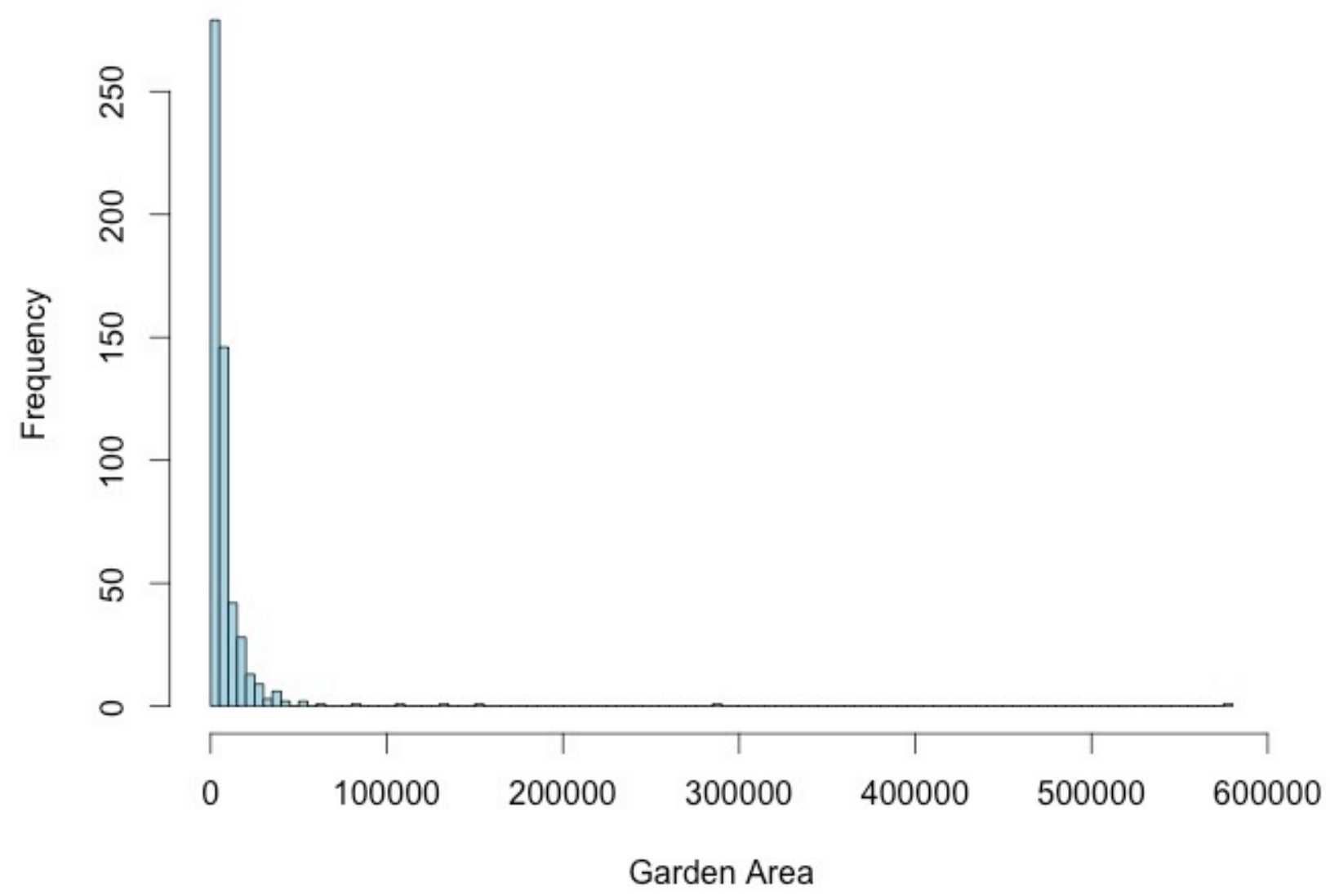

Figure 9: Histogram showing the distribution of community garden areas 
Clearly there are a few outliers in the data. For example, if we were to remove the five community gardens that are over 100,000 sq. ft., we'd see significant impacts the mean runoff values. The mean runoff for a garden would go from 81 to 47 , a $42 \%$ reduction, whereas that of vacant lots would go from 138 to $124(10 \%)$ and that of residential developments goes from 378 to 315 (17\%). Thus the difference in runoff between community gardens and other land uses is starker for smaller parcels, which make up most of the gardens in New York City. However in order to maintain all relevant data points in the community gardens dataset this analysis will continue with using all gardens in the dataset (including potential outliers).

The larger the rain event, the more community gardens retain runoff in comparison to vacant lots and residential areas, but the less they retain proportionally to total rainfall. For a 1.5" rain event, depending on the soil type, community gardens can retain less water than a vacant lot or residential development, but at the 5 " level, community gardens always retain more. Community gardens might therefore be included as a strategy for the mitigation of the effects of climate change, particularly increased storm intensity and flooding rates.

In both storms, community gardens retain more stormwater than vacant lots, which retain more water on average than residential lots, but the maximum values show that they can sometimes retain less (Figure 10). Mean $Q$ values for vacant lots, community gardens, and residential developments for a 1.5 " rain event are $0.24,0.06$, and 0.53 , respectively. This is approximately a 4:1:9 ratio. For a 5 " rain event, $Q$ values are $2.3,1$, and 3.5 respectively. 
Thus the water-holding capacity of community gardens is higher relative to the other land uses during smaller (more common) rain events.

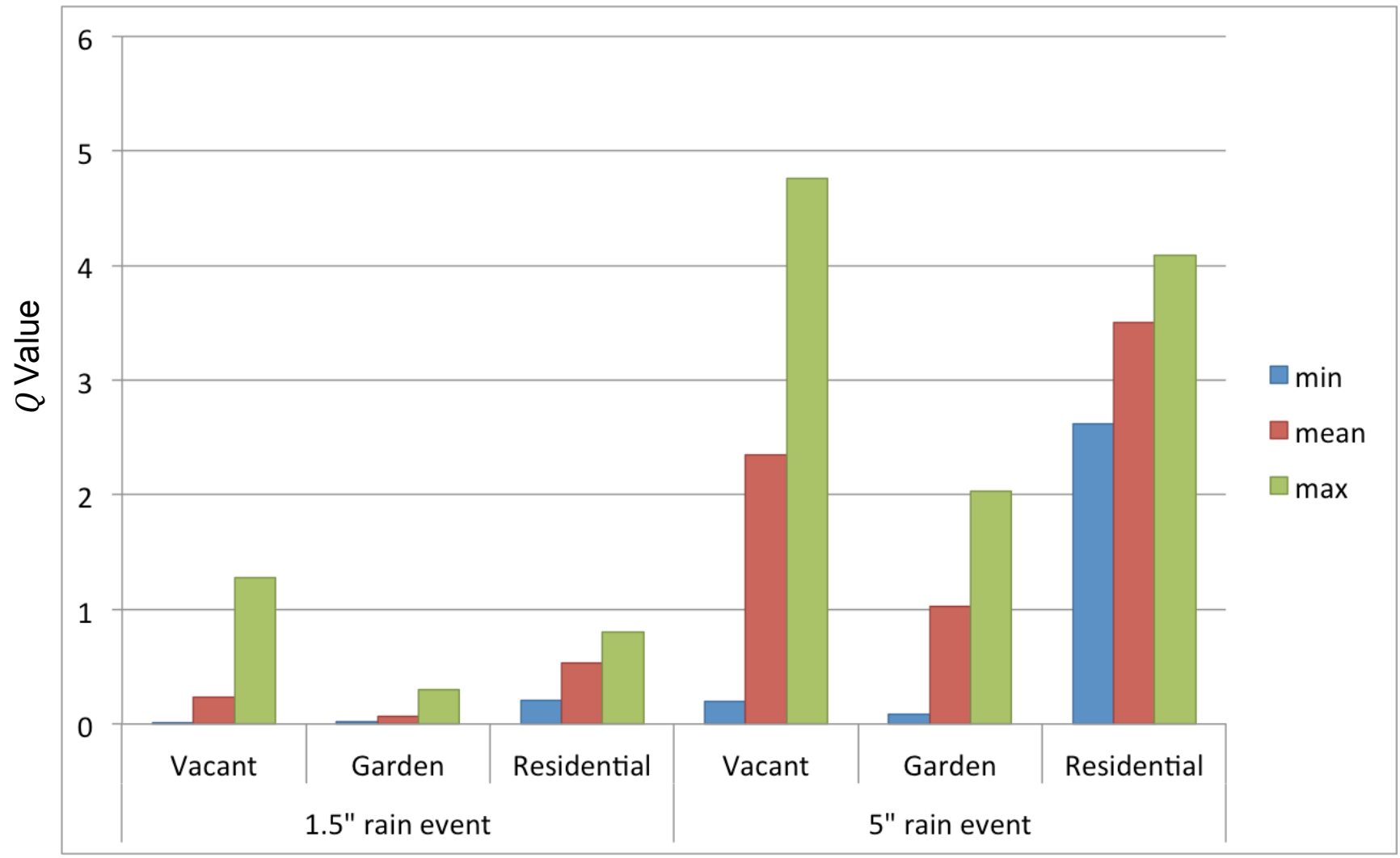

Figure 10: $Q$ values for vacant lots, community gardens, and residential lots

The mean runoff value found for vacant lots, $Q=2.3$, is lower than the $37 \%$ stormwater retention rate that McPhearson, Kremer, and Hamstead (2013) found for vacant lots in New York City for a 5" rain event, which is equivalent to a $Q$ value of 3.15 (63\% runoff). This may be because the lots used in this study are known to be green space, whereas the dataset for all vacant lots in New York City includes other land uses on impervious surfaces. For both types of rain events, for each inch of precipitation, community gardens retain up 
to 2.3-4 times more water than vacant lots and 3.5-9 times more water than residential developments. For a 5" rain event, vacant lots can release up to $95 \%$ of the volume of a precipitation event as runoff, whereas community gardens can release only up to $40.73 \%$.

Table 7: Maximum estimates for runoff

\begin{tabular}{|l|l|l|}
\hline & $\mathbf{1 . 5}$ " rain event & 5" rain event \\
\hline Total precipitation (gallons) & $\mathbf{4 , 9 3 9 , 9 9 5}$ & $\mathbf{1 6 , 4 6 6 , 6 5 1}$ \\
\hline Runoff from residential lots & $1,517,268$ & $10,954,291$ \\
\hline Retained by residential lots & $3,422,727$ & $5,512,360$ \\
\hline Runoff from vacant lots & 556,276 & $6,285,655$ \\
\hline Retained by vacant lots & $4,383,719$ & $10,180,996$ \\
\hline Runoff from community gardens & 326,840 & $2,684,682$ \\
\hline Retained by community gardens & $4,613,155$ & $13,781,970$ \\
\hline
\end{tabular}

A 5" rain event on the $5,283,418$ sq. ft. (121.3 acres) of community gardens located throughout NYC is equivalent to $16,466,651$ gallons of water. Community gardens would retain up to $13,781,970$ gallons of this total, or $83.7 \%$ (Table 7). The vacant lots that were there prior to being converted into community gardens would have retained only up to $10,180,996$ gallons, or $61.8 \%$. The conversion of these vacant lots into community gardens decreased potential runoff from a 5 " rain event by 3,600,973 gallons, or $57 \%$ of the runoff from vacant lots. Developing housing on these community gardens could actually increase runoff by up to 8,269,609 gallons, or more than triple the amount of runoff from the current community gardens. 
Using mean runoff values, depending on the magnitude of the rain event $\left(1.5^{\prime \prime}-5^{\prime \prime}\right)$, community gardens can decrease runoff from vacant lots by $56 \%-72 \%$ and from residential lots by 70.8\%-87.5\%. Applied to New York City's average annual precipitation of 52.5 inches $(171,253,189$ gallons), the presence of community gardens instead of vacant lots decreases runoff by an average of $19,694,117$ to $45,382,095$ gallons and up to $93,384,364$ 111,913,959 gallons (See Appendix B for calculations). Replacing community gardens with residential developments would increase runoff by an average of 52,745,983 to 84,770,328 gallons.

This would significantly backtrack the City's Green Infrastructure plan, which aims to "capture the first inch of rainfall on $10 \%$ of the impervious areas in combined sewer watersheds through detention or infiltration techniques over 20 years." DEP estimates that, should this effort be successful, it will decrease the amount of water entering the waterways through CSOs by 1.5 billion gallons per year. The estimates for increased runoff if the City were to replace community gardens with housing is $3.5 \%-5.6 \%$ of that 1.5 billion gallons - not an insignificant amount.

\section{M2: An Alternate Approach}

As an alternative to using land cover types to estimate stormwater runoff for vacant lots, we can use curve numbers listed in Table 2.2 in TR-55 under "Open Spaces, Fair Condition" (Michigan Department of Environmental Quality 2013, SEMCOG 2008, CDM 2007)(Table 8) as a comparison with our previous water infiltration rates calculations. For New York City, this will likely be an underestimate, as many of the vacant lots have paved surfaces and 
have actual uses such as private housing, parking lot, and commercial/industrial use (Kremer, Hamstead, and McPhearson 2013). In addition, approximately $60 \%$ of the soil on vacant land is impervious (Ackerman, et al., 2011).

Table 8: Vacant lot curve numbers

\begin{tabular}{|c|c|c|c|c|}
\hline Hydrologic Group & A & B & C & D \\
\hline Vacant Lot CN & 49 & 69 & 79 & 84 \\
\hline
\end{tabular}

To estimate stormwater runoff for community gardens, we can add urban agriculture as a land cover type. In New York City, 80\% of community gardens grow food, typically in raised beds full of compost-amended soil, which retains more water than urban soil. In most cases, though, food production does not cover the entire site, as it might with an urban farm; community gardens are heterogeneous spaces that, in addition to food production, also include ornamental plants, trees, social gathering spaces, compost, and more (Gittleman, Librizzi, and Stone 2010). The proportion of a garden devoted to food production varies widely, from $0.25 \%$ - 74\% (Farming Concrete 2015). Using data on the size and quantity of food-producing raised beds from Farming Concrete and GreenThumb, we can estimate the change in stormwater retention when urban agriculture is added to a previously vacant lot.

Community gardeners and urban farmers typically grow in raised beds filled with topsoil and/or compost. The soil in many cities in the US suffers from heavy metal contamination and compaction due to the legacy of manufacturing, leaded paint and gasoline, and dumping. Growing in raised beds amended with compost with paths covered in wood chips 
can help gardeners avoid contact with toxic soil and raise healthy crops. Amending urban soils with compost can increase stormwater infiltration rates by a factor of 1.5-10.5 (EPA 1999). Another study (Harrison et al 1997) found that amending urban soil with compost at a 2:1 ratio doubled infiltration rates.

Farming Concrete is a New York City-based project that has been helping community gardens, school gardens, and urban farms use a variety of metrics to measure the work that they do since 2010. One of the metrics is food production, and one of the methods for measuring food production is called Crop Count - an inventory of edible crops and area under production. GreenThumb, the branch of the NYC Department of Parks and Recreation that works with community gardens, conducts site visits with its registered gardens. One of the items on the survey is raised beds. These two datasets were combined and analyzed with a third order polynomial regression model $\left(\mathrm{R}^{2}=0.5234\right)$ to model raised bed coverage (total area of raised beds per garden) according to garden size.

The model used a third-order polynomial transformation on the total area of a garden to predict the total area of the garden occupied by raised beds. The formula can be written as:

$y=a_{0} x+a_{1} x+a_{2} x^{2}+a_{3} x^{3}+\varepsilon$

where $a$ is the total area of the garden, and $y$ is the total area of the garden occupied by raised beds, and the polynomial terms are orthogonal with respect to the constant polynomial of degree 0 . Fitting the above equation using ordinary least squares (OLS) regression yields the following set of coefficients (Table 9), with an adjusted $R^{2}$ of 0.5149 . 
In other words, our simple regression model explains just over $50 \%$ of the variation in the total area of gardens occupied by raised beds. All coefficients and the F-statistic of 61.14 on 3 and 167 degrees of freedom are significant at the 95\% confidence level (p-value < 0.05 ). Two additional modes (a simple linear model and a second order polynomial model) are given in Figure 11 for comparison. Note the improved fit of the polynomial models with larger values for both total raised beds area and total garden area.

Table 9: Model coefficients

\begin{tabular}{|l|l|l|l|l|}
\hline & Estimate & Std. Error & t value & $\operatorname{Pr}(<|\mathbf{t}|)$ \\
\hline Intercept & 969.77 & 61.08 & 15.878 & $0.000^{* * *}$ \\
\hline Linear model & 9988.83 & 798.68 & 12.507 & $0.000^{* * *}$ \\
\hline 2nd order polynomial & 3754.87 & 798.68 & 4.701 & $0.000^{* * *}$ \\
\hline 3rd order polynomial & 1770.16 & 798.68 & 2.216 & $0.028^{*}$ \\
\hline \multicolumn{2}{|c|}{ Signif. codes: 0 ***' $0.001^{* * *} 0.01^{* * \prime} 0.05 '^{\prime \prime} 0.1^{\prime \prime} 1$} \\
\hline
\end{tabular}




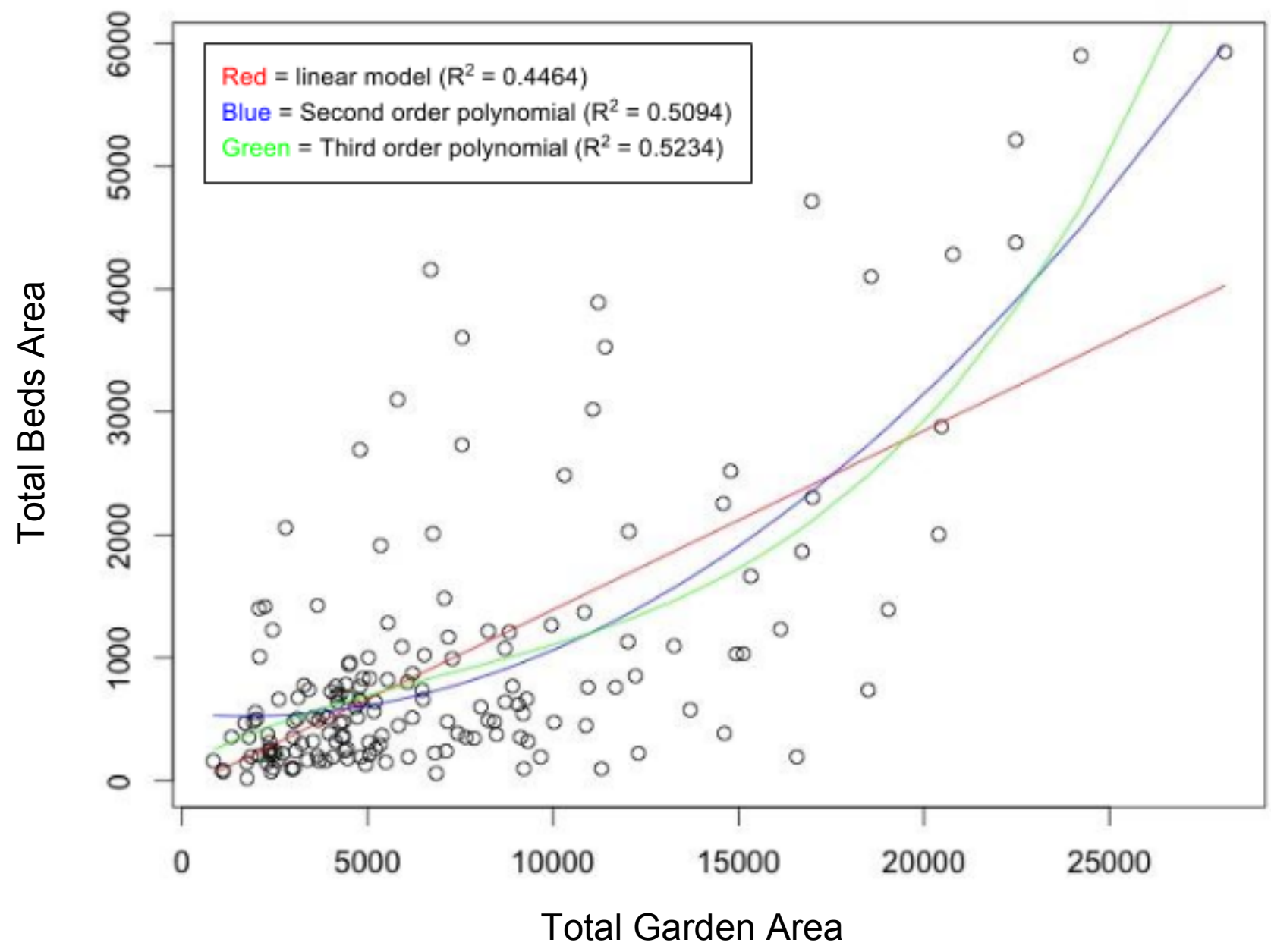

Figure 11: Scatterplot of raised beds areas and garden areas (square feet) with lines fitted to three models: linear, second order polynomial, and third order polynomial

Using the above model, we are able to estimate raised bed coverage for community gardens without raised bed data. Values for raised bed coverage for gardens without raised bed data were estimated using this model. A "contained planter box" has been estimated to have a CN value of 48 based on the TR-55 values for brush-weed-grass mixture with $>75 \%$ ground cover and soil type B (Portland Stormwater Management Manual 2014). We can 
also use the low end of the results from the studies on compost-amended soils to double infiltration rates in raised beds over vacant lots (EPA 1999, Harrison 1997).

Raised beds were added into both vacant lot models to measure the effect on runoff. For the first model that used land cover (M1), raised bed area was subtracted from "green" space. If available green space was too low, the remaining area was subtracted from "paved." New weighted CN values were calculated based on these new land cover types. For the second model (M2), that uses CN values for vacant lots based on hydrologic soil groups, raised bed area was subtracted from the total garden area, and a new weighted $\mathrm{CN}$ value was calculated (see Formula 4, p. 40).

Based on the addition of raised beds at a CN value of 48, we have the following new $Q$ values (see Table 10 and Figure 13). $Q$ values are represented as percentages of total rainfall in Table 11. 


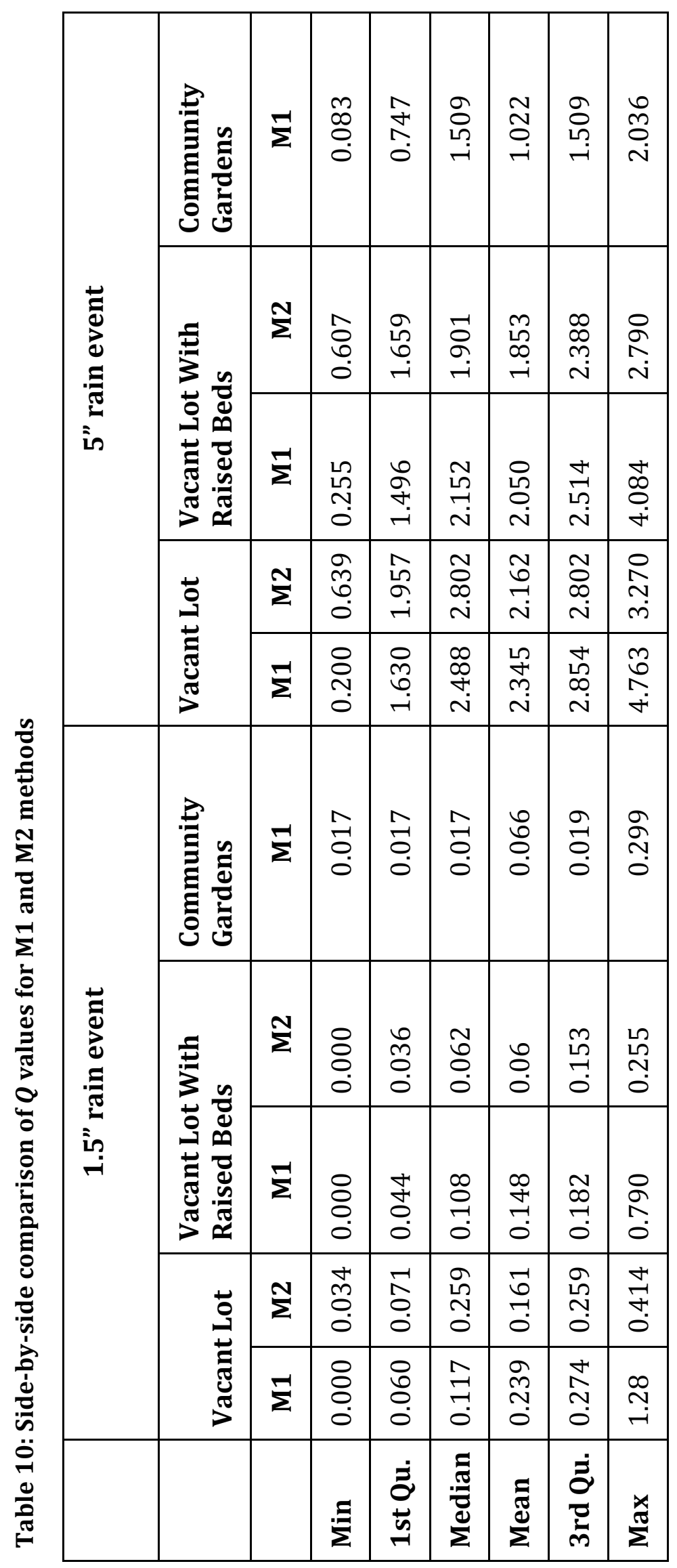




\begin{tabular}{|c|c|c|c|c|c|c|c|c|}
\hline \multirow{5}{*}{ 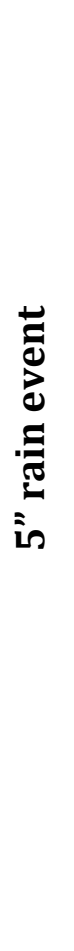 } & 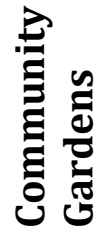 & $\bar{\Sigma}$ & مِ & $\begin{array}{l}\overrightarrow{+} \\
\dot{+}\end{array}$ & $\begin{array}{l}\infty \\
\stackrel{\infty}{+} \\
\stackrel{m}{0}\end{array}$ & $\begin{array}{l}\stackrel{+}{+} \\
\stackrel{N}{ }\end{array}$ & $\begin{array}{l}\infty \\
\stackrel{-}{-1} \\
0 \\
\text { m. }\end{array}$ & \begin{tabular}{l}
$\hat{N}$ \\
\multirow{+}{*}{}
\end{tabular} \\
\hline & \multirow{2}{*}{ 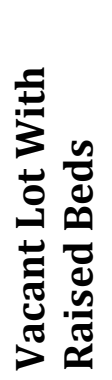 } & $\stackrel{N}{\Sigma}$ & $\underset{⿱ 乛}{\stackrel{\sim}{\sim}}$ & $\begin{array}{l}\infty \\
\stackrel{\infty}{m}\end{array}$ & $\begin{array}{l}\text { Na } \\
\infty \\
\infty \\
m\end{array}$ & $\begin{array}{l}0 \\
0 \\
\hat{m}\end{array}$ & 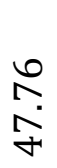 & $\begin{array}{l}\circ \\
\infty \\
\text { in } \\
\text { ஸी }\end{array}$ \\
\hline & & $\vec{\Sigma}$ & 을 & $\begin{array}{l}\text { ๙े } \\
\text { }\end{array}$ & $\begin{array}{l}\dot{\sigma} \\
\text { ஸे }\end{array}$ & $\begin{array}{l}\stackrel{8}{\circ} \\
\underset{+}{+}\end{array}$ & 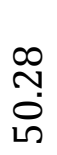 & 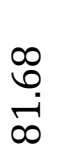 \\
\hline & \multirow{2}{*}{ 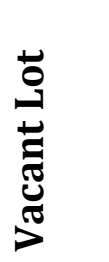 } & $\stackrel{\mathfrak{N}}{\Sigma}$ & $\begin{array}{l}\infty \\
\stackrel{\infty}{\sim} \\
\stackrel{\sim}{\sim}\end{array}$ & $\begin{array}{l}\overrightarrow{+} \\
\stackrel{+}{m}\end{array}$ & 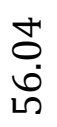 & $\begin{array}{l}\stackrel{+}{\sim} \\
\text { r }\end{array}$ & $\begin{array}{l}\text { ठ } \\
\text { ڤొ }\end{array}$ & $\begin{array}{l}\text { ㅇ. } \\
\text { ஸृ }\end{array}$ \\
\hline & & $\stackrel{F}{\Sigma}$ & $\begin{array}{l}8 \\
\text { ஓ }\end{array}$ & $\begin{array}{l}\stackrel{0}{0} \\
\text { ஸे } \\
\text { no }\end{array}$ & $\begin{array}{l}0 \\
\stackrel{\sigma}{\sigma} \\
\stackrel{\sigma}{*}\end{array}$ & 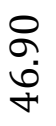 & $\begin{array}{l}\infty \\
0 \\
\text { ஸ̂. }\end{array}$ & $\begin{array}{l}\text { v } \\
\text { ஸे } \\
\text { an }\end{array}$ \\
\hline \multirow{5}{*}{ 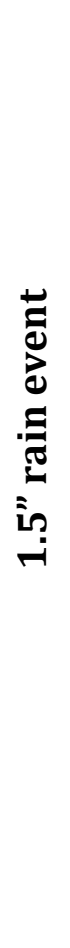 } & 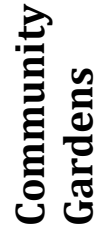 & $\stackrel{F}{\Sigma}$ & $\stackrel{n}{\rightarrow}$ & ¿্' & $\stackrel{m}{\stackrel{n}{-}}$ & $\begin{array}{l}\stackrel{\circ}{+} \\
\dot{f}\end{array}$ & $\widehat{ָ}$ & $\begin{array}{l}n \\
\sigma \\
\sigma \\
\sigma\end{array}$ \\
\hline & \multirow{2}{*}{ 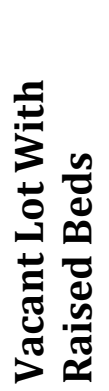 } & $\stackrel{N}{\Sigma}$ & \begin{tabular}{l}
8 \\
\hdashline
\end{tabular} & 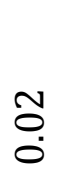 & $\stackrel{m}{\stackrel{m}{*}}$ & \begin{tabular}{l}
8 \\
\hdashline \\
\end{tabular} & 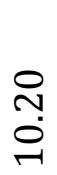 & $\begin{array}{l}8 \\
8 \\
\end{array}$ \\
\hline & & $\stackrel{ㄱ}{\Sigma}$ & \begin{tabular}{l}
8 \\
\hdashline
\end{tabular} & $\begin{array}{l}n \\
0\end{array}$ & 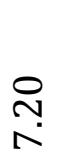 & $\begin{array}{l}\hat{\infty} \\
\sigma\end{array}$ & $\underset{\sim}{\stackrel{m}{\sim}}$ & $\begin{array}{l}\hat{\sigma} \\
\text { ஸे }\end{array}$ \\
\hline & \multirow{2}{*}{ 苞 } & $\stackrel{N}{\Sigma}$ & $\underset{\sim}{\sim}$ & $\stackrel{n}{\stackrel{n}{\gamma}}$ & $\stackrel{\widetilde{N}}{\stackrel{N}{\sim}}$ & 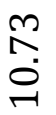 & $\stackrel{\widetilde{N}}{\curvearrowright}$ & $\begin{array}{l}\stackrel{0}{0} \\
\text { Ñ}\end{array}$ \\
\hline & & $\stackrel{\nabla}{\Sigma}$ & $\begin{array}{l}\text { ○ } \\
\text { ○. }\end{array}$ & $\stackrel{8}{\circ}$ & $\begin{array}{l}\stackrel{一}{\infty} \\
\stackrel{1}{0}\end{array}$ & 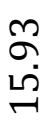 & $\begin{array}{l}\widehat{N} \\
\stackrel{\infty}{\sim}\end{array}$ & $\begin{array}{l}m \\
n \\
\infty \\
\infty\end{array}$ \\
\hline & & & $\Sigma$ & 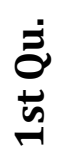 & 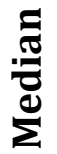 & 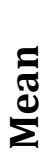 & $\frac{\dot{\Xi}}{2}$ & 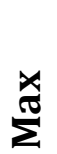 \\
\hline
\end{tabular}


Using the land cover dataset (M1), for a 1.5" rain event, food-producing raised beds can decrease runoff from vacant lots by up to $38.3 \%$, and converting the space to a full garden can decrease runoff by up to $76.6 \%$. For a 5" rain event, raised beds can decrease runoff from vacant lots by $14.3 \%$, and conversion to a garden can reduce runoff by up to $57.3 \%$.

Using CN values for vacant lots from TR-55 Table 2.2 (M2), food-producing raised beds can decrease runoff from vacant lots by up to $38.4 \%$ and garden conversion can decrease runoff by up to $27.8 \%$ for a 1.5 " rain event. For a 5 " rain event, raised beds can decrease runoff by up to $14.7 \%$ and garden conversion by up to $37.7 \%$.

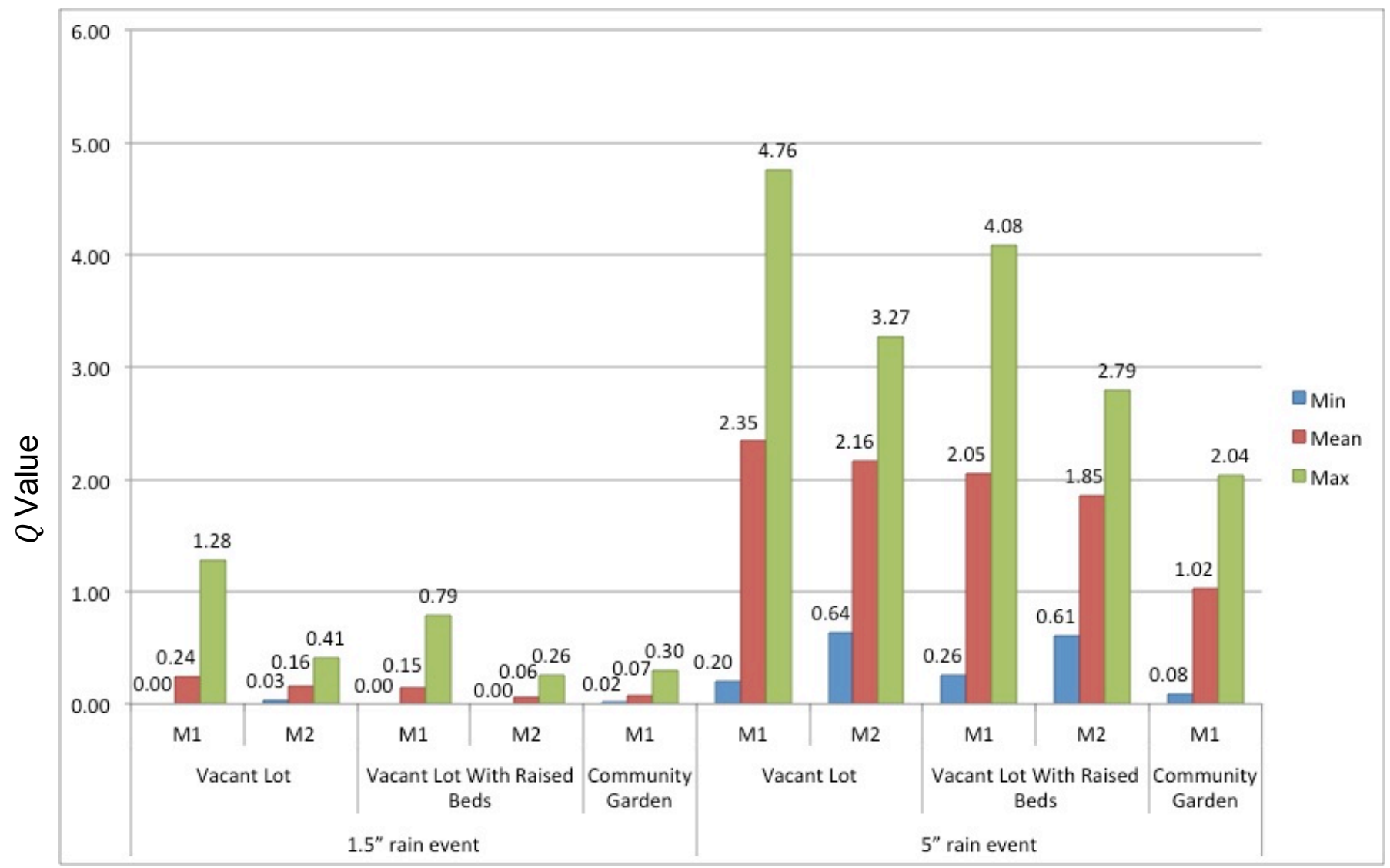

Figure 12: Side-by-side comparison of $Q$ values for M1 and M2 methods 
There is a wide range of variability in the effect of garden conversion on the stormwater retention capabilities of a vacant lot (Figure 12). Because vacant lots in New York City are such heterogeneous spaces, it may not be appropriate to use one set of CN values for all of the parcels, as we do in M2. According to this analysis, in some cases, adding raised beds does not contribute to decreased stormwater runoff, but in other cases, it makes a significant impact. Using the land cover dataset to differentiate vacant lots with lots of impervious surface and those without may improve the accuracy of this analysis, and more accurate land cover classifications would certainly improve things further.

\section{Case Study: Gardens on Land in HPD Jurisdiction}

It is unlikely that New York City policy-makers will choose to convert all community gardens to residential areas en masse. However, they have at times decided to sell a group of community gardens to developers all at once: in the late 1990s, then-Mayor Rudy Giuliani tried to sell over 200 gardens for development, and at the time of this writing, Mayor Bill de Blasio has authorized an affordable housing plan that allows Housing Preservation and Development (HPD) to sell 17 community gardens to developers. In both cases, the decision-making process was not transparent. Partially due to a dearth of useful data, the community gardens vs. affordable housing debate is often framed solely from the standpoint of tax revenue from the lot itself (Voicu and Been 2008, Lin, Philpot, and Jha 2015), without considering the additional economic benefits provided by the ecosystem services produced by community gardens. As such, data quantifying the ecosystem services provided by community gardens was likely not factored into the creation of this list. 
In this case study, we look at the outcomes of running this study on the select group of community gardens included in the Request for Qualifications (RFQ) released by HPD on January 14,2015 . The RFQ asks developers to submit proposals for affordable housing for a list of 181 sites, mostly in East Harlem, Bedford Stuyvesant, East New York, and Brownsville (Tortorello 2015). Residents are using 17 of those sites as community gardens, most using interim-use licenses that stated that the gardens were temporary land uses until the City could afford to develop. With over 1,100 lots in their jurisdiction, however, it was unclear why community gardens had been targeted for development, especially in neighborhoods with high populations of low income residents and histories of disinvestment. Using the M1 method with land cover data, we can estimate the impact of these 17 community gardens under the jurisdiction of Housing Preservation and Development (HPD) have on stormwater runoff, to provide a more detailed picture of the benefits of community gardens (Table 12).

Table 12: Stormwater runoff and retention from 17 community gardens in HPD jurisdiction included in the January 2014, 2015 Request for Qualifications, with comparisons to vacant lots and residential lots

\begin{tabular}{|l|l|l|}
\hline & $\mathbf{1 . 5}$ ' rain event & 5" rain event \\
\hline Total precipitation (gallons) & $\mathbf{7 1 , 7 6 8}$ & $\mathbf{2 3 9 , 2 2 7}$ \\
\hline Runoff from residential lots & 26,328 & 169,820 \\
\hline Retained by residential lots & 45,440 & 69,406 \\
\hline Runoff from vacant lots & 7,118 & 105,223 \\
\hline Retained by vacant lots & 64,650 & 134,003 \\
\hline Runoff from community gardens & 3,044 & 52,271 \\
\hline Retained by community gardens & 68,724 & 186,956 \\
\hline
\end{tabular}


These 17 gardens cover a total of 76,757 square feet (1.7 acres). A 5" rain event would be equivalent to 239,227 gallons. Keeping these sites as community gardens retains 186,956 gallons (78\%), while converting them to housing would retain only 69,406 gallons (29\%). Vacant lots, what these spaces were before being converted into community gardens, would retain 134,003 gallons (56\%). For a 1.5" rain event (71,768 gallons), community gardens would retain 68,724 gallons (96\%), vacant lots would retain 64,650 gallons (90\%), and residential developments would retain 45,440 gallons (63\%).

Runoff from community gardens during a 1.5" rain event would be 23,285 gallons ( $32 \%$ of total precipitation) less than that from residential developments--an $88 \%$ decrease from residential development levels. From a 5" rain event, the decrease in runoff from residential developments would be $49 \%$ of total precipitation, or $69 \%$ of the runoff from residential developments. Over the course of a year, 2,511,878 gallons fall on these 17 gardens. Depending on the scales of the rain events, 100,475-552,613 gallons of stormwater become runoff. If they were replaced with housing, these values increase to $828,919-1,230,820$ gallons of stormwater that become runoff annually. While this is only approximately $0.1 \%$ of the DEP's reduction goal, it still points to a worrying development trend. 


\section{DISCUSSION}

The results of this study are comparable to findings in the literature, which indicate that community gardens should help absorb stormwater runoff in comparison to vacant and residential lots due to their soil amending practices and composting activities (Dunn 2010, Cogger 2015). Compost can increase the porosity and water retention capacity of compacted, compromised urban soils, and some municipalities are experimenting with greening vacant lots as a form of green infrastructure through the application of compost and managed vegetation (Washington State Department of Ecology 2001; Yang and Zhang 2011; Cogger 2015; Pennsylvania Horticultural Society 2015). These results can inform New York City's stormwater management practices, making the case for including community gardens and urban agriculture as viable options for green infrastructure.

In addition to improving water percolation through the soil, 132 community gardens also use rainwater-harvesting systems (GrowNYC 2015). These systems collect rainwater from neighboring rooftops and structures in the garden, such as casitas or hoop houses, 
expanding the footprint of the ecosystem services that these spaces provide. The 132 rainwater-harvesting systems have a collective storage capacity of approximately $1,043,000$ gallons of water. Over the course of a year, emptied for the irrigation needs of the garden and filled again during the next rain event, they may ultimately hold more. Adding this amount to annual citywide estimates of stormwater retention in community gardens means that the presence of community gardens instead of vacant lots can decrease runoff by up to $94,427,364$ to $112,956,959$ gallons (using the maximum runoff estimates for vacant lots and community gardens, see Appendix B).

These values are much higher than those calculated using mean runoff values $(19,694,117$ to $45,382,095)$, pointing to the high variability in both land cover types and hydrologic soil group within community gardens and vacant lots. To obtain more accurate results, we would need to incorporate rain event data, to calculate results based on how much rain falls during each rain event over the course of a year. Storms around and below 1.5" are more common in New York than 5" storms, and so the results would likely skew more towards that end. Since the results show that community gardens retain a larger proportion of stormwater during smaller rain events than during heavy rain events, the annual estimate would likely be on the higher end. However even during larger storms, the results show that across all soil types and land cover combinations, community gardens still retain more stormwater than vacant lots and residential developments. With increased rates of flooding and storm intensity due to climate change, the capacity of community gardens to mitigate stormwater runoff will provide important ecosystem services to New York City. 
The most recent publication of the DEP Green Infrastructure Plan highlights updates on the City's initiatives to decrease the amount of stormwater runoff entering the combined sewer system and contributing to combined sewer overflows (DEP 2014). Some of the funding for this plan does go to urban agriculture through the grant program, which has committed \$11.5 million since 2011. In 2013, the New York Restoration Project (NYRP) received grant of $\$ 328,871$ to install permeable pavers, rain gardens, and a bioswale along an adjacent sidewalk, as well as outdoor classroom facilities, at the Gil Hodges Community Garden in Brooklyn. These improvements will allow the garden, with the addition of the sidewalk bioswale, to manage 150,000 gallons of water annually. The DEP estimates that right-ofway bioswales on sidewalks will retain at least 1,000 gallons per storm, so it is unclear how much of this 150,000 gallons will be retained by the garden and how much will be retained by the adjacent bioswale (Hickman 2014). Furthermore, since the New York Restoration Project is a privately managed land trust and all of their sites are maintained by staff members, not the community, it is unclear whether these spaces fall under the same category of "community garden" as those managed by the public. After purchasing over 50 community gardens to save them from the auction block in 2002, NYRP redesigned them with the help of private donors, without the help or input of community members who had been part of the gardens (Eizenberg 2012).

Interestingly, the amount of funds granted to this one garden was equivalent to nearly half of GreenThumb NYC's entire annual budget for serving and supporting over 600 community and school gardens. According to the New York City Community Garden Coalition, GreenThumb's budget in 2011 was around $\$ 800,000$ and funded entirely through federal Community Development Block Grants (NYC Community Garden Coalition 2011). 
Yet due to community investment and management, community gardens already retain an average of $80 \%-95 \%$ of the stormwater that falls on them. An analysis of the costeffectiveness of each management type would yield interesting insight into how the DEP Green Infrastructure Grant Program could efficiently allocate funds to support the continued existence of and creation of new community gardens, and to improve the stormwater retention capacity of those gardens at the lower end of the spectrum.

Similarly, a large grant $(\$ 592,730)$ was allocated to Brooklyn Grange in 2011 for a new commercial rooftop farm that would manage over one million gallons of stormwater annually. Rooftop farms replace an entirely impervious surface - a rooftop - with intensively managed green space. While capital-heavy to build, these spaces produce considerable levels of ecosystem services compared to bare rooftops, including urban heat island effect mitigation, the filtering of air pollutants, decreased building energy load, and decreased structural maintenance of the roof due to protection from weather and ultraviolet rays -- all in addition to runoff mitigation (Yang, Yu, and Gong 2008; Dunn 2010; Lin, Philpot and Jha 2015).

These two examples show that to some extent, the NYC Department of Environmental Protection does see community gardens and urban farms as green infrastructure. However with just two projects funded, and solely through the allocation of grants, there is room for broader inclusion of green infrastructure types. While they would not be the first to identify these land uses as green infrastructure, they would help reframe community gardens as valuable for their ecosystem services in addition to their other products. 
New York City Mayor Bill de Blasio's update to PlaNYC, entitled OneNYC, outlines progress reports and updates to both PlaNYC and the DEP Green Infrastructure Plan. To manage stormwater through green infrastructure, the City is committed to installing 9,000 curbside bioswale gardens by 2018 and to "institutionalize stormwater management into the design of public property, including streets, parks, schoolyards, and public housing." There is an opportunity to include community gardens and urban agriculture into these designs, although the implementation plan for these initiatives has yet to be released at the time of this writing. Community gardens are mentioned in OneNYC not for their stormwater management benefits, however, but for their role in food production, environmental education, and youth employment (p. 135). While food production falls under the umbrella of ecosystem services, the rhetoric around community gardens is limited to these provisions.

A more holistic inclusion of community gardens as green infrastructure across city agencies would help the DEP achieve their goals. For example, while raising the stormwater retention capacity of the Gil Hodges Community Garden and the surrounding sidewalks to 150,000 gallons annually will help prevent combined sewer overflows, developing on 17 HPD community gardens will increase annual runoff by over 700,000 gallons. Nearly half of these gardens (8) are in priority combined sewer overflow areas, and the rest are in eligible areas. Due to the documented lack of transparency around HPD's decision-making process around the lots included in this most recent $\mathrm{RFQ}$, it is unlikely that HPD staff consulted with DEP staff to make sure that their development goals were in line with the 
NYC Green Infrastructure Plan. It is also unclear whether the DEP's stated goal of retaining the first inch of runoff from $10 \%$ of the impervious surfaces in their combined sewer areas will take into account increased development or whether their goal is based on impervious surfaces documented in 2010, when the first report was released. 


\section{CONCLUSIONS}

With municipal governments developing sustainability and green infrastructure plans across the country, research quantifying urban ecosystem services is needed more than ever before. Policy makers need reliable methods and data in order to measure the effectiveness of these programs. Dense urban development leads to heavy burdens on the environment, both local and global, and alters water, air, soil, and wildlife systems. Yet we rely on these systems for keeping our cities livable. Strategies for studying these urban ecological systems are critical to implementing tools for supporting them.

Communities also take part in managing and monitoring urban ecological systems. Through the stewardship of parks, street trees, and community gardens, city residents educate others about the importance of the environment for quality of life and advocate for conservation (Andersson, Barthel, and Ahrne 2007; Connolly et al. 2013). Studies measuring community-based environmental stewardship are scarce, despite the fact that some researchers acknowledged that the participation of stewards is critical to sustaining ecosystem services (Andersson, Barthel, and Ahrne 2007; Barthel 2010; Krasny et al. 2013; 
Andersson et al. 2014). Also called civic ecology, participants in environmental stewardship have also been involved in its measurement, presenting opportunities for data collection that can help policy makers (Krasny et al. 2013). Community gardeners are often considered under the umbrella of environmental stewards and civic ecologists (Andersson, Barthel, and Ahrne 2007; Krasny et al. 2013; Connolly et al. 2013).

Community gardens are valuable resources for ecosystem services and green infrastructure in cities and towns across the United States and globe. Cities around the country are introducing new policies to support community gardens and urban agriculture as sustainability strategies. On Earth Day of 2015, the city of Milwaukee, Wisconsin announced a plan to build 100 new community gardens and thousands of fruit trees within the next year (Stephens 2015). Their goals with this plan include food security, clean air and water, beautification, and quality of life (Dimitrijevic 2015). A California law passed in 2013 allows cities to incentivize private property owners to allow urban agriculture in exchange for a tax break, helping urban farmers with the issue of land tenure (Romney 2013). NeighborSpace in Chicago is a public-private non-profit that acts as a land trust for community gardens and urban farms, protecting them from development (Local Governments Commission). In 2012, Minneapolis changed their zoning codes to make it easier to establish urban agriculture as a land use (Freshwater Society 2013).

In New York City, community gardens make significant contributions to many of the sustainability goals outlined by the city, including PlaNYC and the DEP Green Infrastructure reports. Mayor de Blasio's sustainability plan, OneNYC, mentions community gardens as "essential community resources where people come together to play, learn, grow food, 
exercise, and relax." In this new plan, his administration aims to support community gardens and urban agriculture. As of this writing, his implementation plan has yet to be released.

Each of the methods used in this thesis show that community gardens can manage more stormwater runoff than both vacant and residential lots. Using both methods from the literature and novel approaches using original data, we see that residents who convert vacant lots into community gardens are improving the stormwater retention capacity of the land. Combining land cover data with hydrologic soil group is likely to be a more accurate method for estimating local runoff values, considering soil types and vacant lot qualities vary across municipalities. With better quality land cover data, we can produce better estimates of just how much stormwater community gardens prevent from entering our water systems.

The results of this study show that community gardens are producing ecosystem services through stormwater management, preventing up to 113 million gallons of stormwater from entering combined sewer systems annually. The Department of Environmental Protection frames its runoff reduction goals in reference to the amount of impervious surface in its combined sewer areas with a target of a $10 \%$ reduction in runoff by 2030 (DEP 2013). As such, it may help to achieve their reduction targets to introduce policies that support the continuation of community gardens, especially in these priority areas, to prevent losing green space in favor of increased impervious surface areas.

Future research could contribute to empirical measurements of stormwater runoff in a variety of vacant lots, community gardens, and urban farms. Rather than estimating a curve 
number using data from 1986 that relies on an approximation of land cover type, we need original data that looks at community gardens with and without food production, with and without structures like greenhouses and rainwater harvesting systems, etc. Vacant lots, too, are heterogeneous - some contain trees, some a lot of rubble and impervious surface area, and some are cared for by the municipality while some are not. Better information about how these sites handle stormwater will better inform analyses like these.

Additional quantitative studies on the various other ecosystem services produced by community gardens are also needed. Community gardens compost organic waste, diverting it from the waste stream; produce tons of food annually, with a lower carbon footprint than conventionally grown food shipped from thousands of miles away; plant native flora, providing habitat for biodiversity; mitigate the effect of the urban heat island effect on local temperatures; and provide space for building community, recreation, and opportunities for environmental education. Understanding how these services fit in with cities' sustainability plans will help build an understanding of their role in the urban environment.

New York City is leading the way for green infrastructure and climate change adaptation. Municipalities worldwide are watching how New York City implements its plans for sustainability and resilience. The City has an opportunity to take the lead on community gardens and urban agriculture, supporting community-based endeavors that help achieve the goals listed in PlaNYC, OneNYC, and the NYC Green Infrastructure Plan. Understanding the role that community gardens play in the provision of ecosystem services in New York City can help us better understand their role in urban sustainability worldwide. 


\section{APPENDIX A}

\section{Cleaning the community garden dataset from GrowNYC (2015)}

Some of the gardens in New York City's community garden shapefile were drawn incorrectly or were not community gardens. When overlaid on the land cover dataset, it became clear that some of the land cover classifications were incorrect. Below are some examples of gardens that were identified as problematic.

- Edited community gardens polygons:

- Floyd Bennett Field - misplaced dozens of yards away from actual garden location

- Astoria Residents Rebuilding Our World (ARROW) - whole neighboring building included as part of the garden, redrew the polygon to include just the garden

- Magical Garden - misplaced on a nearby roof

- Sterling Community Group Garden - polygon drawn incorrectly

- Deleted records that are not community gardens

- School gardens

- Passages Academy

- JFK HS The Enchanted Garden

- GEC Greenhouse Program

- Hope of Israel - senior citizen center outdoor recreation area - not a community garden

- Little Green Garden - demolished in 2008, combined with Jardin La Roca/Rock Garden

- Mini Barrio Garden - demolished

- Itliba Herbal Garden - address given is a building

- St. Francis of Assisi Peace Garden - not a community garden

- St. Francsis of Assisi [other garden] - not a community garden

- St. Mark's Lutheran Church Garden - no garden

- United Garden - actual use: driveway

- Nothing Yet Community Garden - bulldozed within one year of breaking ground

- Garden Beautiful / West 153rd St. Harlemite - no garden

- Ancient Order of Gardeners - no garden

- Examples of gardens that are labeled "paved" when they should be tree cover or bare earth

- LDC of Broadway

- Vinegar Hill

- Melrose New Generation

- Centro Cultural Rincon Criollo - aerial 
- 400 Montauk Avenue Block Association Garden

- Grant Avenue Community Garden

- Lincoln Road Garden

- Prophecy Garden Church of God - not even sure this is a garden

- Essex St Community Garden 


\section{APPENDIX B}

\section{Estimating stormwater runoff for annual rainfall of 52" using mean values:}

Total gallons of water on community gardens in NYC for a given quantity of rain:

$G=\left(\frac{R}{12}\right)(7.48 A)$

where $G$ is total gallons of water, $R$ is rainfall in inches, $A$ is the area of land in feet, and 7.48 is a constant translating cubic feet to gallons.

$G=\left(\frac{52}{12}\right)(7.48 * 5,238,418)=171,253,189$ gallons

Calculate the difference in gallons of runoff for two different land uses:

$G_{d}=(G)\left(P_{1}-P_{2}\right)$

where $G_{d}$ is the difference in gallons of runoff for a given rain event between two land uses, $G$ is the total gallons of stormwater from equation $6, P_{1}$ is the percent runoff from the first land use and $P_{2}$ is the percent runoff from the second land cover type.

Calculate the percent difference in runoff for two different land uses:

$P_{d}=\frac{G_{d}}{\left(P_{1}\right)(G)}$

where $P_{d}$ is the percent difference in runoff, $G_{d}$ is the difference in gallons of runoff for a given rain event between two land uses from equation $7, P_{1}$ is the percent runoff from the first land use from equation 7, and Gis the total gallons of stormwater from equation 6 .

These equations were used to calculate the difference in stormwater runoff between vacant lots and community gardens using 1.5 " and 5 " rain events as a range, using mean and maximum percent runoff values for comparison (Table 13). 
Table 13: Mean and maximum percent runoff for vacant lots and community gardens, as recorded in Tables 5 and 6.

\begin{tabular}{|l|l|l|l|l|}
\hline & \multicolumn{2}{|l|}{ Vacant Lot } & \multicolumn{2}{l|}{ Community Garden } \\
\hline & $\mathbf{1 . 5}$ " storm & $\mathbf{5}$ " storm & $\mathbf{1 . 5}$ " storm & 5" storm \\
\hline Mean \% runoff & 0.1591 & 0.4689 & 0.044 & 0.204 \\
\hline Max \% runoff & 0.8534 & 0.9526 & 0.1999 & 0.4073 \\
\hline
\end{tabular}

$G_{d}$ and $P_{d}$ values where $P_{1}$ represents the value for vacant lots and $P_{2}$ represents the value for community gardens (Table 14 ):

Table 14: $G_{d}$ and $P_{d}$ values for the difference in runoff between vacant lots and community gardens.

\begin{tabular}{|l|l|l|l|l|}
\hline & \multicolumn{2}{|l|}{$G_{d}$} & \multicolumn{2}{l|}{$P_{d}$} \\
\hline & $\mathbf{1 . 5}$ " storm & 5" storm & $\mathbf{1 . 5}$ " storm & 5" storm \\
\hline Mean runoff & $19,711,242$ & $45,382,095$ & 0.72 & 0.56 \\
\hline Max runoff & $111,913,959$ & $93,384,364$ & 0.766 & 0.57 \\
\hline
\end{tabular}

Comparing residential lots and community gardens (Table 15):

Table 15: Mean and maximum percent runoff for residential lots and community gardens, as recorded in Tables 5 and 6.

\begin{tabular}{|l|l|l|l|l|}
\hline & \multicolumn{2}{|l|}{ Residential Lot } & \multicolumn{2}{l|}{ Community Garden } \\
\hline & $\mathbf{1 . 5}$ " storm & $\mathbf{5}$ " storm & $\mathbf{1 . 5}$ " storm & 5" storm \\
\hline Mean \% runoff & 0.3522 & 0.6999 & 0.044 & 0.204 \\
\hline Max \% runoff & 0.5339 & 0.8179 & 0.1999 & 0.4073 \\
\hline
\end{tabular}


$G_{d}$ and $P_{d}$ values where P1represents the value for residential lots and P2represents the value for community gardens (Table 16):

Table 16: $G_{d}$ and $P_{d}$ values for the difference in runoff between residential lots and community gardens

\begin{tabular}{|l|l|l|l|l|}
\hline \multicolumn{2}{|l|}{$G_{d}$} & $P_{d}$ \\
\hline & $\mathbf{1 . 5}$ " storm & $\mathbf{5 "}$ storm & $\mathbf{1 . 5 ”}$ storm & 5” storm \\
\hline Mean runoff & $52,780,233$ & $84,924,456$ & 0.875 & 0.708 \\
\hline Max runoff & $57,198,565$ & $70,316,559$ & 0.626 & 0.502 \\
\hline
\end{tabular}




\section{REFERENCES}

596acres.org. 2015. Statement by Council Member Robert Cornegy.

http://596acres.org/en/news/2015/02/10/council-member-robert-cornegy-asks-mayorto-save-gardens/ Accessed April 21, 2015.

Ackerman, K., Plunz, R., Conrad, M., Katz, R., Brennan, S., and Culligan, P. 2011. The Potential for Urban Agriculture in New York City: Growing Capacity, Food Security, and Green Infrastructure. Urban Design Lab, The Earth Institute, Columbia University. http://www.urbandesignlab.columbia.edu/sitefiles/file/urban_agriculture_nyc.pdf Accessed April 30, 2015).

Alaimo K., Packnett, E., Miles, R., and Kruger, D. 2008. "Fruit and vegetable intake among urban community gardeners." Journal of Nutrition Education and Behavior. 40(2):94-101.

Alexander, F., and Powell, L. 2011. "Neighborhood Stabilization Strategies for Vacant and Abandoned Properties." Zoning and Planning Law Report. p. 2-4.

Anderson, M., and Cook, J. 1999. "Community Food Security: Practice in Need of Theory?" Agriculture and Human Values. 16(): 141-50.

Andersson, E., Barthel, S., and Ahrne, K. 2007. "Measuring the Social-Ecological Dynamics Behind the Generation of Ecosystem Services." Ecological Applications. 17(5): 1267-1278.

Andersson, E., Barthel, S., Borgstrom, S., Colding, J., Elmqvist, T., Folke, C., and Gren, A. 2014. "Reconnecting Cities to the Biosphere: Stewardship of Green Infrastructure and Urban Ecosystem Services." AMBIO. 43:445-453.

Armstrong, D. 2000. "A survey of community gardens in upstate New York: Implications for health promotion and community development." Health Place. 6(4): 319-327.

Baker, L. 2004. "Tending Cultural Landscapes and Food Citizenship in Toronto's Community Gardens." Geographical Review. 94(3): 305-325.

Barthel, S., Folke, C., and Colding, J. 2010. "Social-ecological memory in urban gardensRetaining the capacity for management of ecosystem services." Global Environmental Change. 20:255-265.

Branas, C., Cheney, R., MacDonald, J., Tam, V., Jackson, T., and Ten Have, T. 2011. “A Difference-in-Differences Analysis of Health, Safety, and Greening Vacant Urban Space." American Journal of Epidemiology. 174(11): 1296-1306. 
Burkhard, B., Alkemade, R., Crossman, N., Nedkov, S., and Petz, K. 2014."Quantifying ecosystem services and indicators for science, policy and practice." Editorial. Ecological Indicators. 37: 161-162.

Campbell, M. 2004. "Building a Common Table: The Role for Planning in Community Food Systems." Journal of Planning Education and Research 23(4).

Claro, A., Formato, T., Huyhua, S., Lock, R., Martineau, K., Moore, A., Michaelides, P., O'Neal, E., Ruge, S., Santner, A, and Trotman, L. 2013. "Leveraging the Multiple Benefits of Green Infrastructure." Sustainability Management Capstone Project for New York City's Department of Environmental Protection. Columbia University.

Center for Neighborhood Technology. 2007. "Green Values Stormwater Calculator Methodology." http://greenvalues.cnt.org/calculator/methodology.php Accessed January 31, 2015.

Center for Neighborhood Technology. 2009. "National Green Values Calculator Methodology." http://greenvalues.cnt.org/national/calculator.php Accessed January 31, 2015.

Chicago Metropolitan Agency for Planning (CMAP). 2010. “Go To 2040: Comprehensive Regional Plan." Chicago, Illinois. http://www.cmap.illinois.gov/documents/10180/17842/GO-TO-2040-short-plan_10-72010_FINAL.pdf/2840498d-96fa-43fa-9784-9c8f364b4547

Clifton, K. 2004. "Mobility Strategies and Food Shopping for Low-Income Families: A Case Study." Journal of Planning Education and Research. 23(4).

Cogger, C. 2005. "Potential Compost Benefits for Restoration Of Soils Disturbed by Urban Development." Compost Science \& Utilization. 13(4): 243-251.

Communities and Local Government. 2007. "Climate Change and Urban Green Spaces." Neighbourhoods, Cities, and Regional Analysis Division. http://www.cchangeproject.org/rnav/65.jsp Accessed April 30, 2015.

Connolly, J., Svendsen, E., Fisher, D., and Campbell, L. (2013) “Organizing urban ecosystem services through environmental stewardship governance in New York City." Landscape and Urban Planning. 109(1): 76-84.

Cooley, D., and Olander, L. 2012. "Stacking Ecosystem Services Payments: Risks and Solution." Environmental Law Reporter. 42(2): 10150-10165.

Cowling, R., Egoh, B., Knight, A., O’Farrell, P., Reyers, B., Rouget, M., Roux, D., Welz, A., and Wilhelm-Rechman, A. 2008. "An operational model for mainstreaming ecosystem services for implementation." Proceedings of the National Academy of Sciences. 105(28): 94839488. 
C-SNAP at Boston Medical Center and The Philadelphia Grow Project at Drexel University. 2008. "Coming up Short: High food costs outstrip food stamp benefits." The Real Cost of a Healthy Diet.

Curtis, H. 1915. “Vacant Lots.” The Journal of Education. 81(17): pp.458-458.

Davies, Z., Edmondson, J., Heinemeyer, A., Leake, J., and Gaston, K. 2011. "Mapping an urban ecosystem service: quantifying above-ground carbon storage at a city-wide scale." Journal of Applied Ecology. 48: 1125-1134.

DEP 2010. NYC Green Infrastructure Plan: A Sustainable Strategy for Clean Waterways. NYC Department of Environmental Protection.

http://www.nyc.gov/html/dep/html/stormwater/nyc_green_infrastructure_plan.shtml Accessed October 20, 2014.

DEP 2012. Guidelines for the Design and Construction of Stormwater Management Systems. NYC Department of Environmental Protection.

http://www.nyc.gov/html/dep/html/stormwater/nyc_green_infrastructure_plan.shtml Accessed October 20, 2014.

DEP 2013. New York City Green Infrastructure Combined Sewer Area Reference Map. http://www.nyc.gov/html/dep/pdf/green_infrastructure/green_infrastructure_combined sewer_reference_map.pdf Accessed February 15, 2015.

DEP 2014. DEP Green Infrastructure Shapefile. NYC OpenData. Available at https://data.cityofnewyork.us/Environment/DEP-Green-Infrastructure/496p-fwvq Accessed February 15, 2015.

DEP 2015. “Types of Green Infrastructure." http://www.nyc.gov/html/dep/html/stormwater/combined_sewer_overf low_bmps.shtml

Accessed January 31, 2015.

Design Trust for Public Space. 2012. "Five Borough Farm: Seeding the Future of Urban Agriculture in New York City." Self-published.

Dimitrijevic, M. 2015. "This Earth Day, Invest in Access to Healthy Food." Milwaukee Wisconsin Journal Sentinel. April 21, 2015. http://www.jsonline.com/news/opinion/thisearth-day-invest-in-access-to-healthy-food-b99485755z1-300841761.html Accessed April $24,2015$.

Dunn, A. 2010. “Citing Green Infrastructure: Legal and Policy Solutions to Alleviate Urban Poverty and Promote Healthy Communities." Boston College Environmental Affairs Law Review. 3(1): 41-66. 
Edmonson, J., Davies, Z., Gaston, K., and Leake, J. 2014. “Urban cultivation in allotments maintains soil qualities adversely affected by conventional agriculture." Journal of Applied Ecology. 51: 880-889.

Eizenberg, E. 2012. "The Changing Meaning of Community Space: Two Models of NGO Management of Community Gardens in New York City." International Journal of Urban and Regional Research. 36(1): 106-2.

Environmental Protection Agency (EPA). 1999. "Infiltration Through Disturbed Urban Soils and Compost Amended Soil Effects on Runoff Quality and Quantity." EPA Publication No. 600R-00016.

Environmental Protection Agency (EPA). 2011. "Evaluation of Urban Soils: Suitability for Green Infrastructure or Urban Agriculture.” EPA Publication No. 905R1103.

Environmental Protection Agency (EPA). 2014. "Enhancing Sustainable Communities with Green Infrastructure." EPA 100-R-14-006.

http://www2.epa.gov/sites/production/files/2014-10/documents/greeninfrastructure.pdf

Environmental Protection Agency (EPA). 2014b. “The Stormwater Calculator: Identifying Green Infrastructure Solutions." http://www2.epa.gov/sites/production/files/201410/documents/swc_fact_sheet_updated_2014_0.pdf

Farming Concrete. 2015. Crop Count data for New York City Community Gardens. http://farmingconcrete.org/mill. Accessed 3/1/2015.

Flood, J. 2010. The Fires: How a Computer Formula, Big Ideas, and the Best of Intentions Burned Down New York City--and Determined the Future of Cities. Riverhead Books: New York.

Freshwater Society. "Urban Agriculture as a Green Stormwater Management Strategy." 2013.

http://www.arboretum.umn.edu/UserFiles/File/2012\%20Clean\%20Water\%20Summit/F reshwater\%20Urban\%20Ag\%20White\%20Paper\%20Final.pdf Accessed April 25, 2015.

Garcia, Kathryn, on behalf of the New York City Department of Sanitation. 2014. "Local Law 77 of 2013 Organics Collection Pilot Program Program Report, through March 2014." http://www1.nyc.gov/assets/dsny/downloads/pdf/studies-andreports/OrganicsCollection-LL77-DiversionReportI-2014.pdf Accessed April 7, 2015.

Garcia, Kathryn, Commissioner of the New York City Department of Sanitation. Letter to Antonio Reynoso, New York City Council Chair of the Committee on Sanitation. March 23, 2015. http://596acres.org/en/news/2015/03/26/sanitation-commissioner-responds-tocouncil-member-reynoso-on-disposition-of-hpd-land-developed-as-gardens-and-compostsites/Accessed April 7, 2015 
Garvin, E., Cannuscio, C., and Branas, C. 2013. "Greening vacant lots to reduce violent crimes: a randomized controlled trial." Injury Prevention. 19:198-203.

Gedzelman, S., Austin, S., Cermak, R., Stefano, N., Partridge, S., Quesenberry, S., and Robinson, D. 2003. "Mesoscale aspects of the urban heat island around New York City." Theoretical Applied Climatology. 75(1-2): 29-42.

George, D. 2013. "Harvesting the biopsychosocial benefits of community gardens." American Journal of Public Health. 103(8): e6-e6.

Gittleman, M., Librizzi, L., and Stone, E. 2010. “Community Garden Survey. New York City Results 2009/2010." New York City.

Gittleman, M., Jordan, K., and Brelsford, E. 2012 “Using Citizen Science to Quantify Community Garden Crop Yields." Cities and the Environment. 5(1): Article 4.

Goldman, R. and Tallis, H. 2009. "A Critical Analysis of Ecosystem Services as a Tool in Conservation Projects: The Possible Perils, the Promises, and the Partnerships."

The Year in Ecology and Conservation Biology, New York Academy of Sciences. 1162: 6378.

GreenThumb NYC. 2014. "About GreenThumb." Brochure, NYC Department of Parks and Recreation. http://www.greenthumbnyc.org/pdf/greenthumb-brochure_3-10-14.pdf Accessed April 7, 2015.

GrowNYC. “GrowNYC 2014 Annual Report.” http://www.grownyc.org/about/annualreport_financials Accessed April 7, 2015.

GrowNYC. 2015. Community Gardens Database.

GrowNYC 2015b. Rainwater Harvesting Systems in Community Gardens Database.

Haase, D., Larondelle, N., Andersson, E., Artmann, M., Borgstrom, S., Breuste, J., GomezBaggethun, E., Gren, A., Hamstead, Z., Hansen, R., Kabisch, N., Kremer, P., Langemeyer, J., Rall, E., McPhearson, T., Pauleit, S., Qureshi, S., Schwarz, N., Voigt, A., Wurster, D., and Elmqvist, T. 2014. "A Quantitative Review of Urban Ecosystem Service Assessments: Concepts, Models, and Implementation." AMBI0. 43:413-433.

Harrison, R., Grey, M., Henry, C., and Xue, D. 1997. "Field Test of Compost Amendment to Reduce Nutrient Runoff." Prepared for the City of Redmond. College of Forestry Resources, University of Washington, Seattle. May.

Hickman, M. 2014. “Meet the Bioswale, New York's New Weapon in the War Against Water Pollution." Mother Nature Network. http://www.mnn.com/earth-matters/climate- 
weather/blogs/meet-the-bioswale-new-yorks-new-weapon-in-the-war-against-water Accessed May 3, 2015.

ICLEI - Local Governments for Sustainability. "100 Mayors adopt Seoul Declaration for sustainable cities." April 9, 2015.http://www.iclei.org/details/article/96-mayors-adoptseoul-declaration-for-sustainable-cities.html Accessed April 29, 2015.

International Panel on Climate Change (IPCC). 2014. "Climate Change 2014: Impacts, Adaptation, and Vulnerability." http://www.ipcc.ch/report/ar5/wg2/ Accessed March 25, 2015.

Kern, K., and Alber, G. "Chapter 8: Governing Climate Change in Cities: Modes of Urban Climate Governance in Multi-Level Systems." Competitive Cities and Climate Change, OECD Conference Proceedings. Milan, Italy. October 9-10, 2008.

Krasny, M., Russ, A., Tidball, K., and Elmqvist, T. 2014. “Civic ecology practices: Participatory approaches to generating and measuring ecosystem services in cities." Ecosystem Services. 7:177-186.

Kremer, P., Hamstead, Z., and McPhearson, T. 2013. "A social-ecological assessment of vacant lots in New York City." Landscape and Urban Planning. 120:218-233

Kremer, P., Hamstead, Z., and McPhearson, T. 2015. "The Value of Urban Ecosystem Services: A Spatially Explicit Multicriteria Analysis of Landscape Scale Valuation Scenarios in NYC." In press.

Lawson, L. 2005. City Bountiful: A Century of Community Gardening in America. University of California Press, Berkeley, CA.

Lin, B., Philpot, S., and Jha, S. 2015. "The future of urban agriculture and biodiversityecosystem services: Challenges and next steps." Basic and Applied Ecology, in press.

Local Governments Commission. "Cultivating Community Gardens: The Role of Local Government in Creating Healthy, Livable Neighborhoods."

http://nccommunitygarden.ncsu.edu/RoleLocalGov.pdf Accessed April 24, 2015.

Martellozzo, F. Landry, J., Plouffe, D., Seufert, V., Rowhani, P., and Ramankutty, N. 2014. "Urban agriculture: a global analysis of the space constraint to meet urban vegetable demand." Environmental Research Letters. 9: 1-8.

McCuen, R, and Bondelid, T. 1981. "Relation Between Curve Number and Runoff Coefficient." Journal of the Irrigation and Drainage Division. 107(4): 95-400.

McPhearson, T., Kremer, P., and Hamstead, Z. (2013) “Mapping urban ecosystem services in New York City: Applying a social-ecological approach in urban vacant land." Ecosystem Services. 5: 11-23. 
McPhearson, T., Hamstead, Z., and Kremer, P. (2014) "Urban Ecosystem Services for Resilience Planning and Management in New York City." AMBIO. 43:502-515.

Mees, C., and Stone, E. 2012. "Zoned Out: The Potential of Urban Agriculture Planning to Turn Against its Roots." Cities and the Environment. 5(1): Article 7.

Meyers, S., Beyer-Clow, L., Daniel, G., LoVerde, K., Rodriguez-Ochoa, E., Seaman, T., and Zaplatosch, J. 2014. "Community Based Green Infrastructure Solutions: Changing how we manage stormwater." Openlands. http://www.openlands.org/filebin/pdf/CommunityBased_Green_Infrastructure_Solutions___Openlands.pdf Accessed March 15, 2015.

Millenium Ecosystem Assessment (2005).

http://www.millenniumassessment.org/en/index.html Accessed March 15, 2015.

Mogilevich, M. 2014. “What was, and is, Urban Renewal in New York City?” Urban

Reviewer. http://www.smartsign.com/urbanreviewer/\#map=12/40.7400/73.9462\&page=essays.html Accessed May 4, 2015.

Nemore, C. 1998. "Rooted in Community: Community Gardens in New York City, A Report to the New York State Senate." New York Senate Minority Office. http://www.cityfarmer.org/NYcomgardens.html Accessed March 18, 2015.

New York City. 2007. "PlaNYC: A Greener, Greater New York." New York, NY: The City of New York Office of the Mayor.

New York City. 2008. "PlaNYC: Sustainable Stormwater Management Plan." New York, NY: The City of New York Office of the Mayor.

New York City. 2010. "PlaNYC: Sustainable Stormwater Management Plan, Progress Report October 2010." New York, NY: The City of New York Office of the Mayor.

New York City. 2011. “PlaNYC: Update April 2011." New York, NY: The City of New York Office of the Mayor.

New York City Panel on Climate Change (NPCC). 2015. "Building the Knowledge Base for Climate Resiliency: New York City Panel on Climate Change 2015 Report." New York, NY: The City of New York. Office of the Mayor.

New York City. 2015. “OneNYC: The Plan for a Strong and Just City." New York, NY: The City of New York Office of the Mayor.

NYC Community Garden Coalition. 2010. "Where We Stand and How We Got Here: An Introduction to the Current Legal Status of Our Community Gardens." http://nyccgc.org/about/history/Accessed March 18, 2015. 
NYC Community Garden Coalition. 2011. “Rally to Save GreenThumb!” Blog post. http://nyccgc.org/2011/04/rally-to-save-greenthumb-tue-05-apr/ Accessed May 3, 2015.

Pace University. 2015. "Vacant, Abandoned, and Distressed Property Legal Research Guide.” http://libraryguides.law.pace.edu/vacant accessed 4/15/15.

Pataki, D., Carreiro, M., Cherrier, J., Grulke, N., Jennings, V., Pincet, S., Pouyat, R., Whitlow, T., and Zipperer, W. 2011. "Coupling biogeochemical cycles in urban environments: ecosystem services, green solutions, and misconceptions." Frontiers in Ecology and the Environment. 9(1): 27-36.

Pennsylvania Horticultural Society. 2015. "Philadelphia LandCare Program." http://phsonline.org/greening/landcare-program Accessed May 3, 2015.

Portland Stormwater Management Manual. January 2014.

https://www.portlandoregon.gov/bes/article/474156

Postel, S., and Thompson, B., Jr. 2005. "Watershed protection: Capturing the benefits of nature's water supply services." Natural Resources Forum. 29(2): 98-108.

Pothukuchi, K., and Kaufman, J. 1999. "Placing the Food System on the Urban Agenda: The Role of Municipal Institutions in Food Systems Planning." Agriculture and Human Values. 16(2): 213-24.

Romney, L. 2013. “New California law aims to cultivate urban agriculture." Los Angeles Times. October 2, 2013. http://articles.latimes.com/2013/oct/02/local/la-me-urbanagriculture-law-20131003 Accessed April 24, 2015.

Rosenfeld, A., Akbari, H., Bretz, S., Fishman, B., Kurn, D., Sailor, D., and Taha, H. 1995. "Mitigation of urban heat island. Materials, Utility Programs, Updates." Energy and Buildings. 22: 255-265.

Rosenzweig, C., Solecki, W., Parshall, L., Gaffin, S., Lynn, B., Goldberg, R., Cox, J., and Hodges, S. 2006. "Mitigating New York City's Heat Island with Urban Forestry, Living Roofs, and Light Surfaces." In: Proceedings of Sixth Symposium on the Urban Environment, January 30-Feburary 2, Atlanta, GA.

Sala, O., Chapin, F., Armesto, J., Berlow, E., Bloomfield, J., Dirzo, R., Huber-Sanwald, E., Huenneke, L., Jackson, R., Kinzig, Ann., Leemans, R., Lodge, D., Mooney, H., Oesterheld, M., Poff, N., Sykes, M., Walker, B., Walker, M., and Wall, D. 2000. "Global Biodiversity Scenarios for the Year 2100." Science 287.5459: 1770.

Saldivar-Tanaka, L. and Krasny, M. 2004. "Culturing Community Development, Neighborhood Open Space, and Civic Agriculture: The Case of Latino Community Gardens in NYC. Agriculture and Human Values. 21: 399-412. 
Salzman, J., Thompson, B., and Daily, G. 2001. "Protecting Ecosystem Services: Science, Economics, and Law." Stanford Environmental Law Journal. 20:309-332.

Sassen, S. 2005. "The Global City: Introducing a Concept." Brown Journal of World Affairs. 11(2): 2-43.

Schmelzkopf, K. 1995. "Urban Community Gardens as Contested Space.” Geographical Review. 85(3): 364-381.

Schukoske, J. 2000. "Community Development through Gardening: State and Local Policies Transforming Urban Open Space." Legislation and Public Policy. 3: 351392.

Smith, C, and Kurtz, H. (2003) "Community Gardens and Politics of Scale in New York City." Geographical Review. 93:2, 193-212.

Soil Survey Geographic Database (SSURGO). Dataset for Hydrologic Soil Groups for New York City. Natural Resources Conservation Service. Accessed January 31, 2015.

Southeast Michigan Council of Governments (SEMCOG). 2014. "Green Infrastructure Vision for Southeast Michigan." http://semcog.org/Plans-for-the-Region/Environment/GreenInfrastructure Accessed April 21, 2015.

Speirs, F., Lindsay, S., and Kirkbridge, F. 1898. "Vacant Lot Cultivation.” Charities Review.

Stephens, A. 2015. "Milwaukee Has Ambitious Designs on Community Gardens, Urban Orchards." Next City. April 24, 2015. http://nextcity.org/daily/entry/cities-environmentjustice-news-for-earth-week Accessed April 24, 2015.

Strickland, C. 2012. "How New York City Leads Green Infrastructure Movement: Blueprint to Achieve Greener Stormwater Systems." Clearwaters. http://nywea.org/clearwaters/122-summer/6.pdf Accessed April 24, 2015.

Taha, H.1997. "Urban climates and heat islands: albedo, evapotranspiration and anthropogenic heat." Energy and Buildings. 25: 99-103.

Tidball, K., and Krasny, M. 2010. "Urban environmental education from a conceptual framework for Civic Ecology Education." Cities and the Environment. 3: 1-20.

Tortorello, M. 2015. “In Community Gardens, a New Weed?” New York Times, February 11, 2015. http://www.nytimes.com/2015/02/12/garden/in-community-gardens-a-newweed.html Accessed April 15, 2015.

United Nations. 2013. State of the World's Cities (2012-2013): Prosperity of Cities. United Nations Human Settlement Program.

http://mirror.unhabitat.org/pmss/listltemDetails.aspx?publicationID=3387 
United States Department of Agriculture (USDA). 1986. “Urban Hydrology for Small Watersheds.” TR-55. Natural Resources Conservation Service: Conservation Engineering Division.

University of Vermont Spatial Analysis Laboratory and New York City Urban Field Station. New York City Landcover 2010 (3ft version) Dataset. Published April 17, 2012. Available at https://nycopendata.socrata.com/Environment/Landcover-Raster-Data-2010-/9auy-76zt

Van der Biest, K., Hondt, R., Jacobs, S., Landuyt, D., Staes, J., Goethals, P., and Meire, P. 2014. "EBI: An index for delivery of ecosystem service bundles." Ecological Indicators. 37: 252265.

Voicu, I., and Been, V. 2008. "The effect of community gardens on neighboring property values.” Real Estate Economics. 36: 241-283.

Wakefield, S., Yeudall, F., Taron, C., Reynolds, J., and Skinner, A. 2007. “Growing urban health: Community gardening in South-East Toronto." Health Promotion International. 22(2): 92-101.

Wasatch Front Regional Council. 2012. "The Wasatch Front Green Infrastructure Plan.” http://wfrc.org/new_wfrc/Green_Infrastructure/\%28Re\%29Connect\%20The\%20Wasatc h\%20Front\%20Green\%20Infrastructure\%20Plan.pdf

Washington State Department of Ecology. 2001. "Stormwater Manual for Western Washington." Volume 5. Publication 99-15.

https://fortress.wa.gov/ecy/publications/publications/0510033.pdf

Winne, M. 2008. Closing the Food Gap: Resetting the Table in the Land of Plenty. Beacon Press: Boston, MA.

Yadav, P., Duckworth, K., and Grewal, P. 2012. "Habitat structure influences below ground biocontrol services: A comparison between urban gardens and vacant lots." Landscape and Urban Planning. 104(2): 238-244.

Yang, J., and Zhang, G. 2011. "Water infiltration in urban soils and its effects on the quantity and quality of runoff." Journal of Soils and Sediments. 11:751-761.

Yang, J., Yu, O., and Gong, P. 2008. "Quantifying air pollution removal by green roofs in Chicago.” Atmospheric Environment. 42:7266-7273.

Zick, C., Smith, K., Kowaleski-Jones, L., Uno, C., and Merrill, B. 2013. "Harvesting more than vegetables: the potential weight control benefits of community gardening." American Journal of Public Health.103(6):1110-1115. 